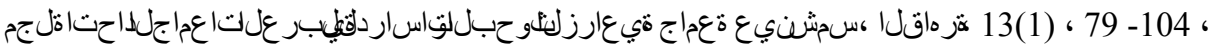
2005

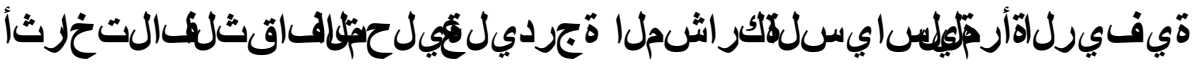
رصنيف

]4

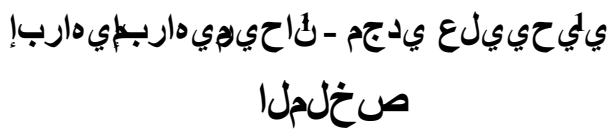

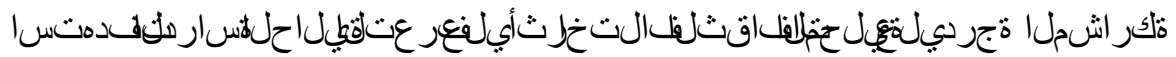

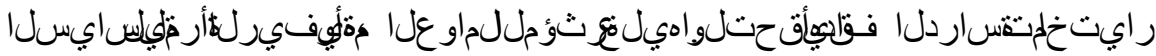

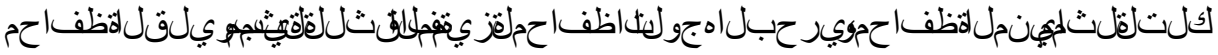

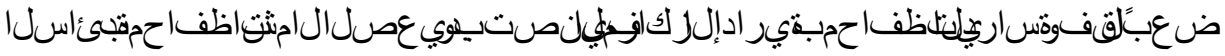

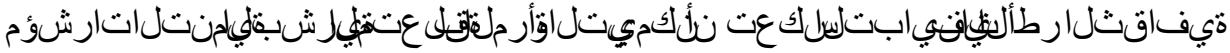

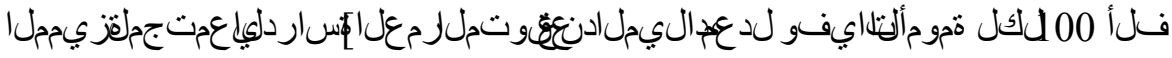

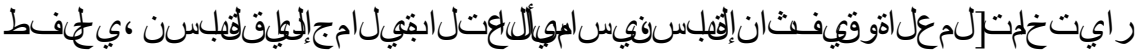

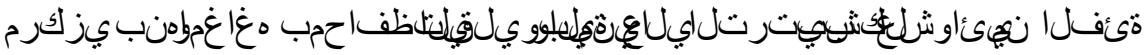

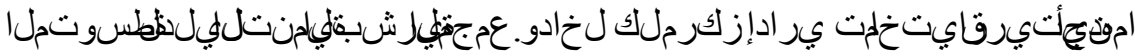

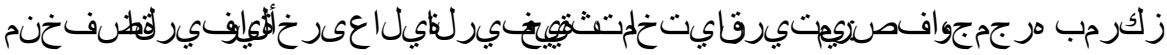

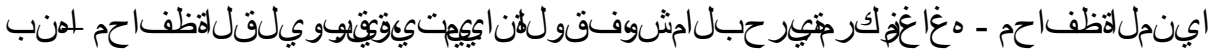

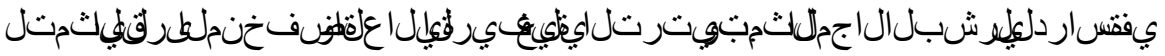

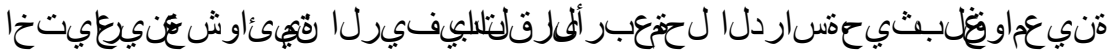

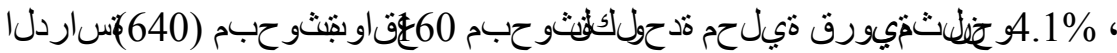

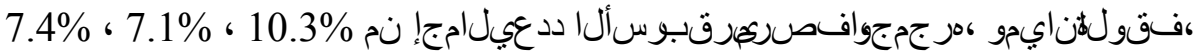

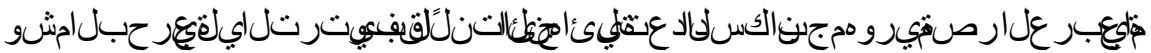

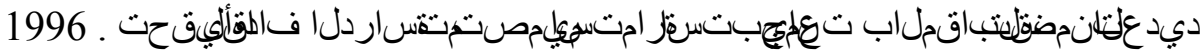

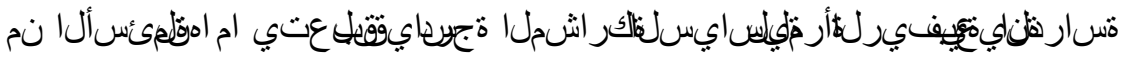

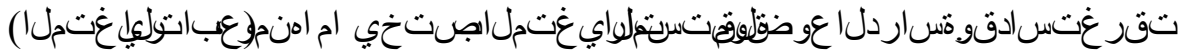

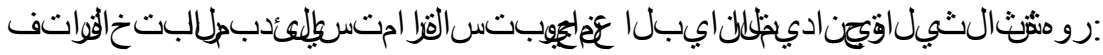

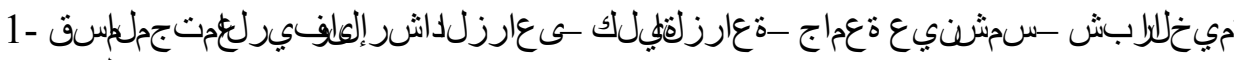

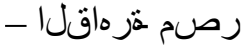




\section{ىبي حناحير}

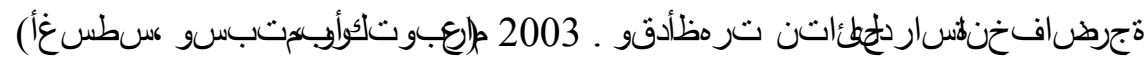

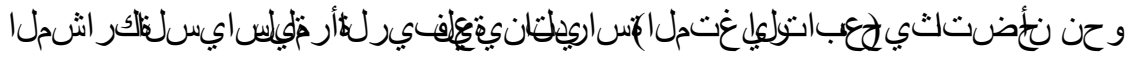

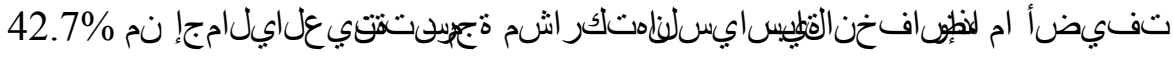

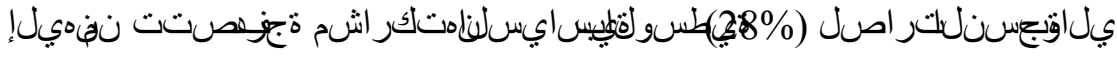

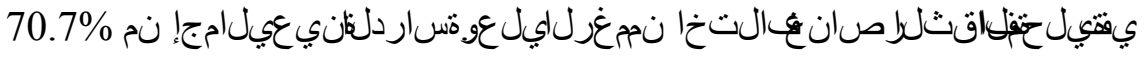

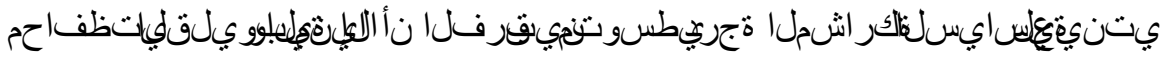

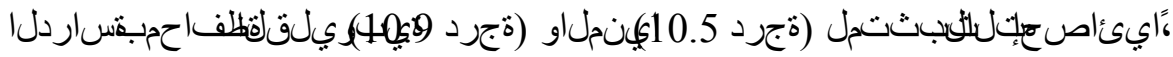

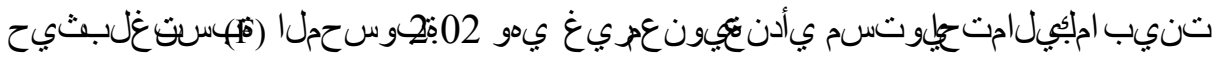

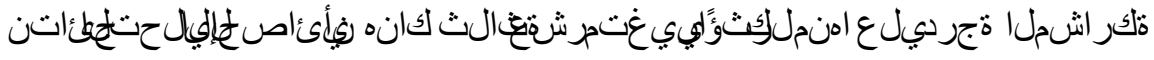

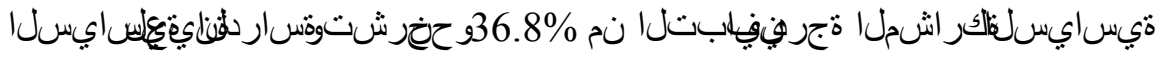

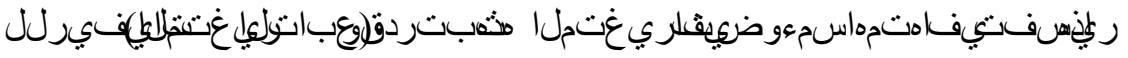

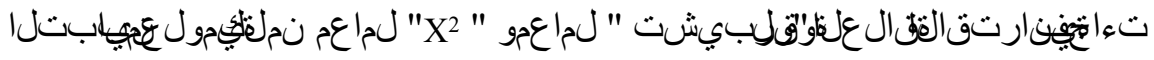

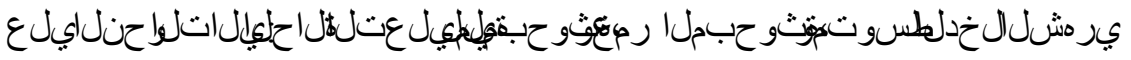

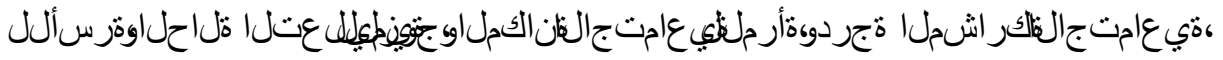

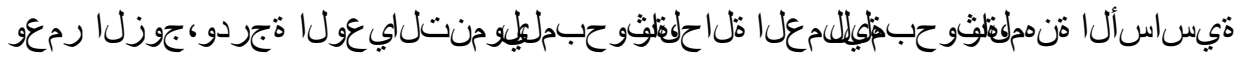

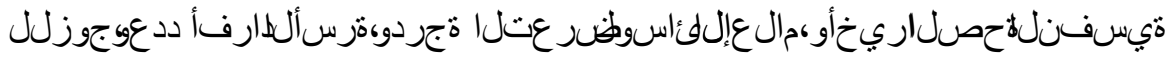

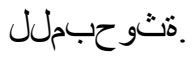

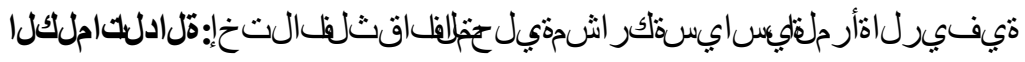

\section{قمدمدقم}

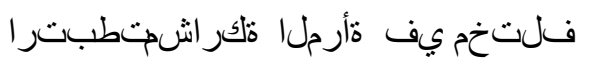

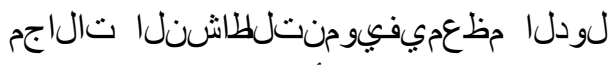

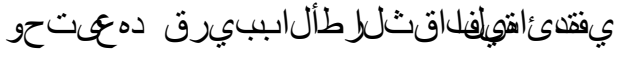

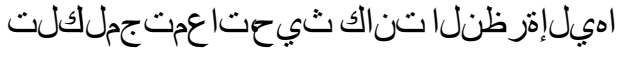

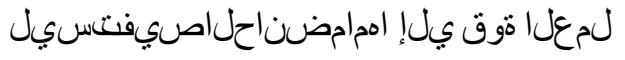

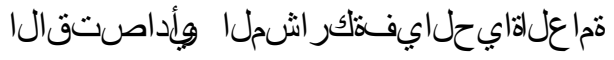

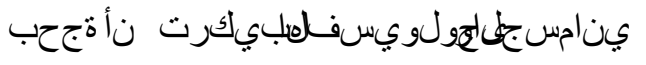

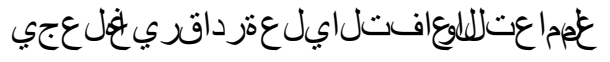

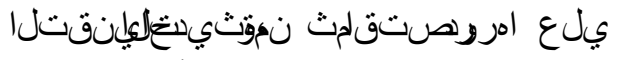

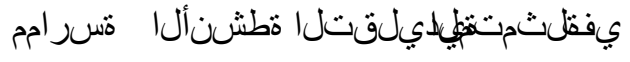

عاذغلازيهجتولافطأل ثياعرو باجنإل

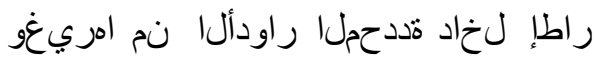

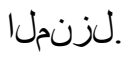

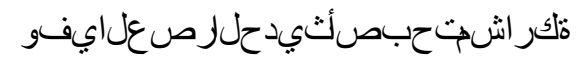

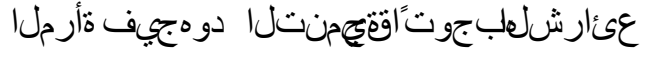

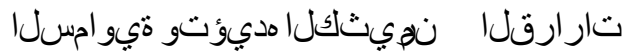

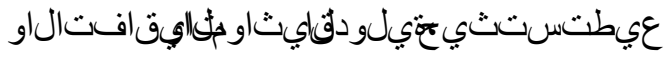

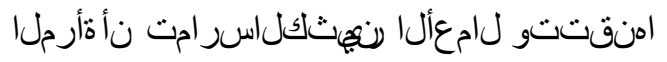

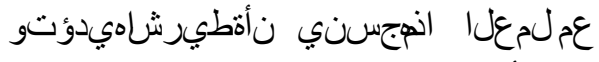

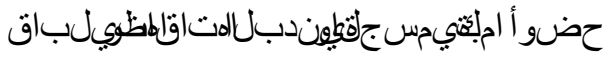

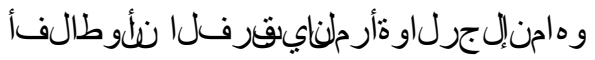




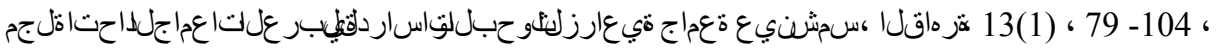
2005

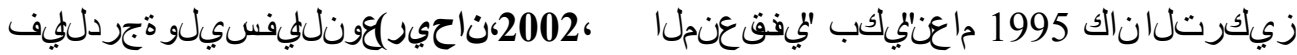
ص 28) .

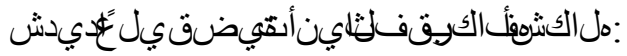

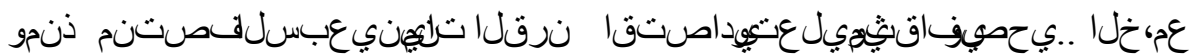

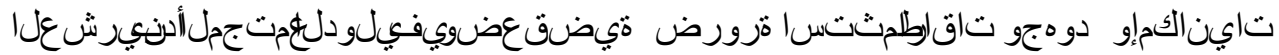

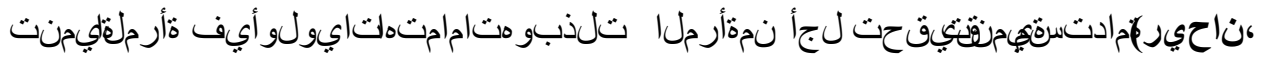

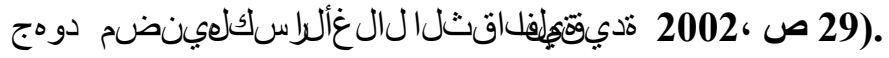

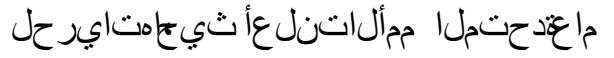

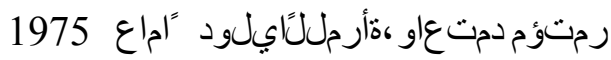

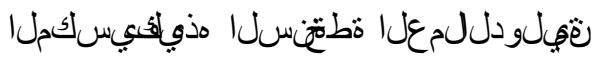

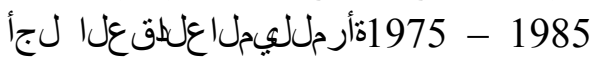
ييتثالث تاعوضوم يلع ماتق يذلاعل:

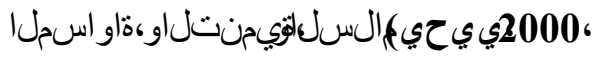

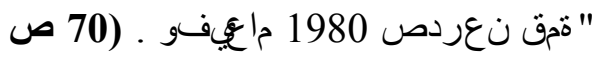

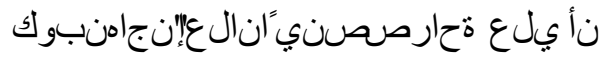

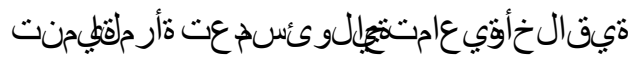

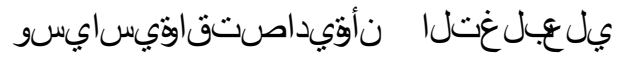

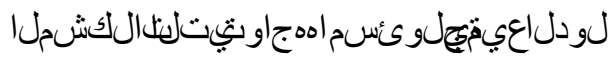

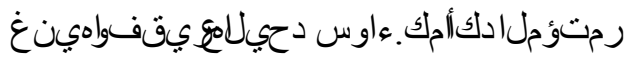
"مالني

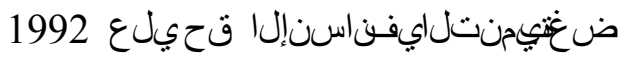
رمتؤحل 'شقانيينو لياوتسملايلعو

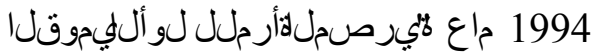

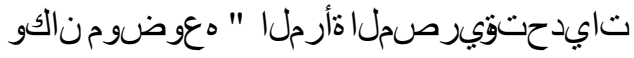

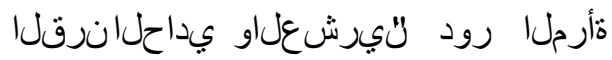

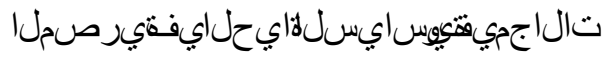

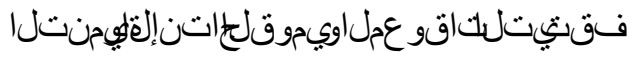

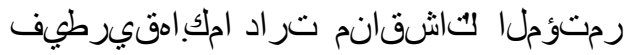

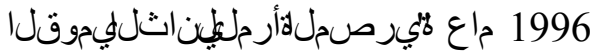

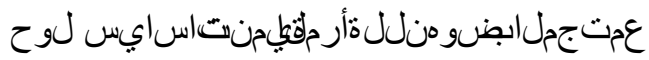

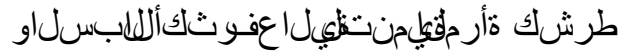

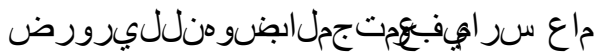

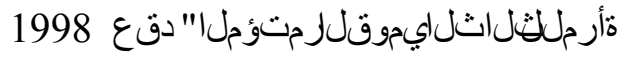

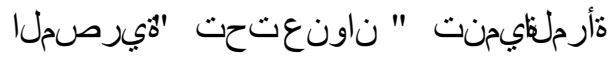

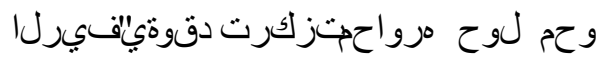

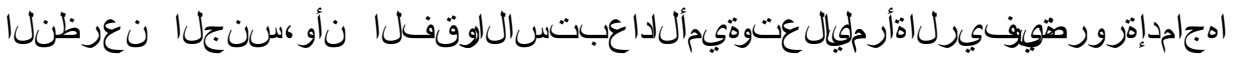

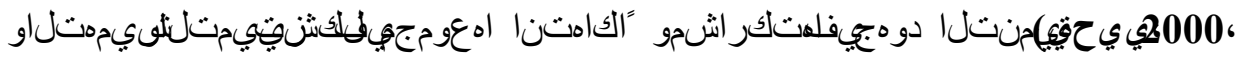

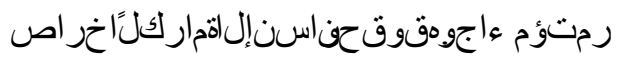

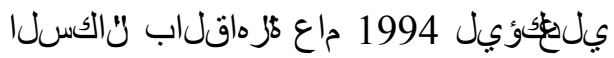

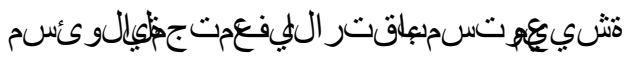

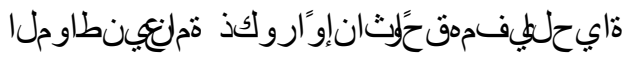

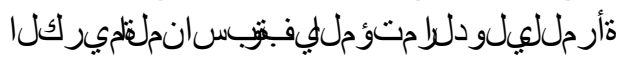
ص 71).

\author{
قساردلكلكشم

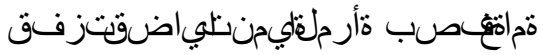

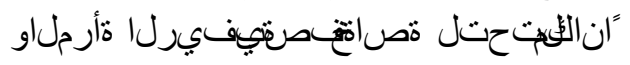

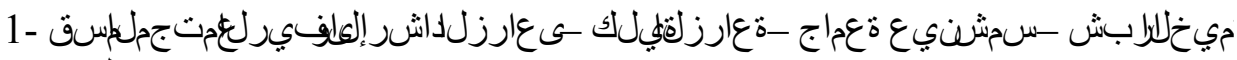
رصم مةرهاقلاقل - 


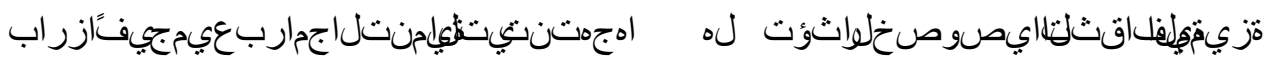

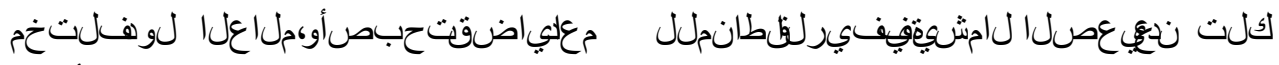

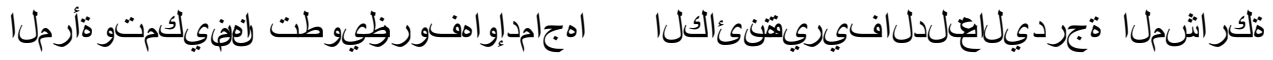

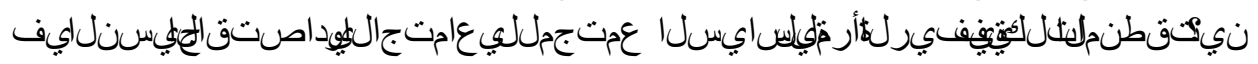

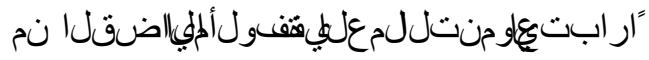

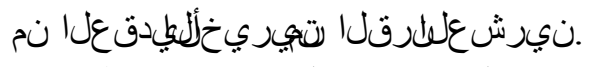

\section{قـساردلا فـادهأ}

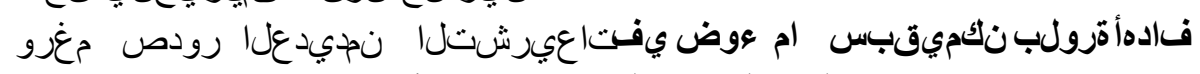

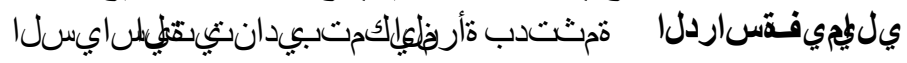

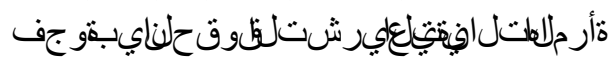

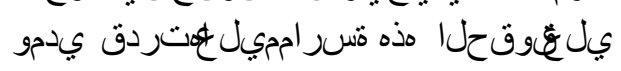

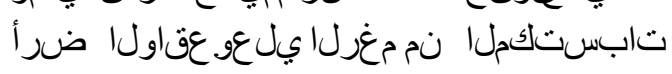

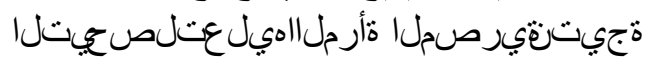

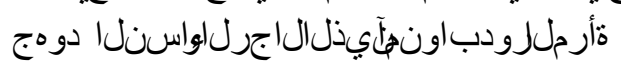

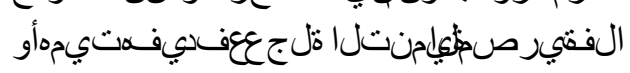

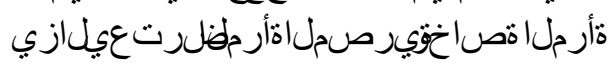

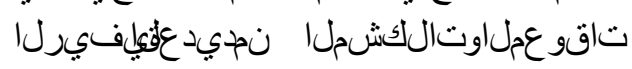

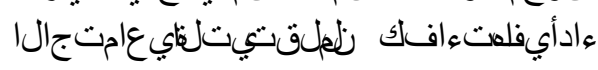

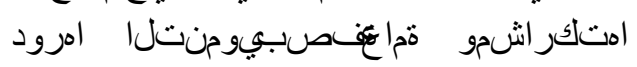

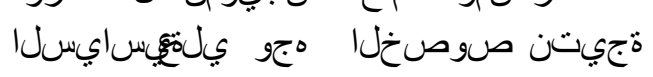

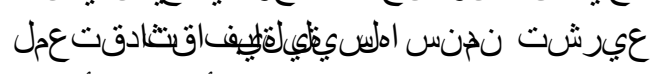

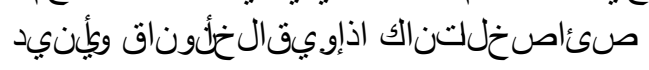

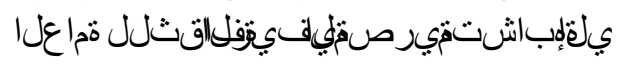

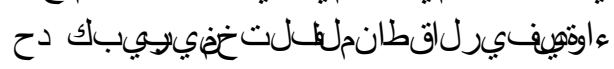

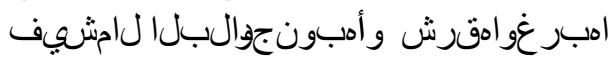

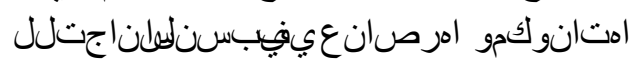

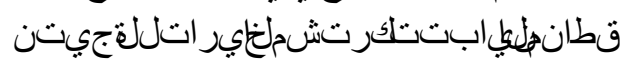

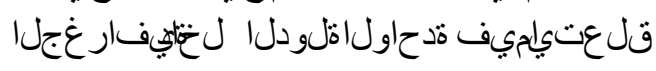

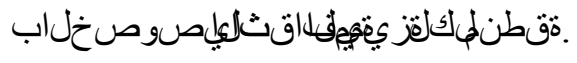

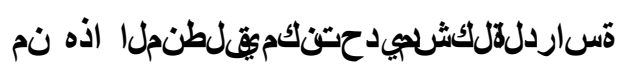
ي تلاتلولاست

تيسايسلقاكر اشملا ةجرديلفعر عتل - 1 -

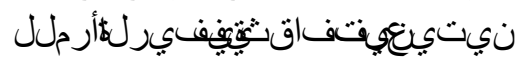

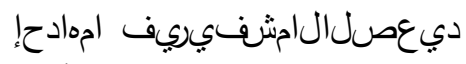

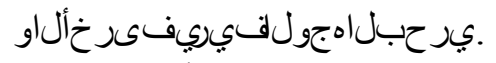

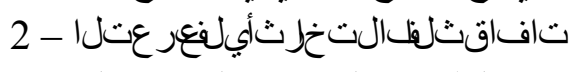

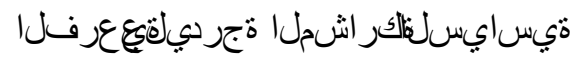

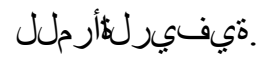

يلغوثؤمل

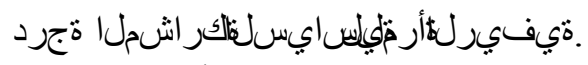

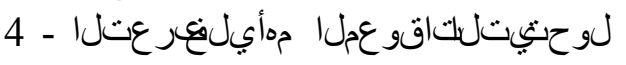

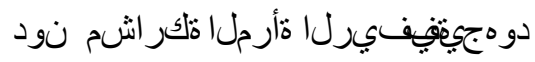

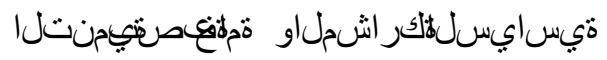
ة.

\section{قساردلميمهافم}

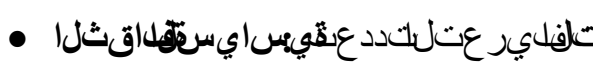

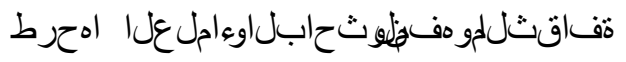

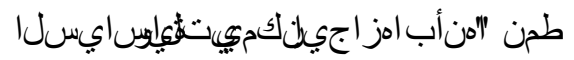

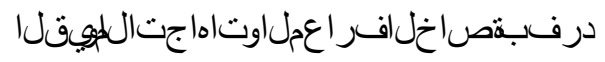

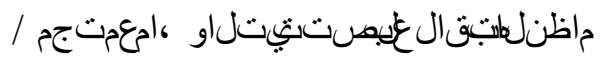
ريغ وأرشابلهكشب عاوسيسايسايسل

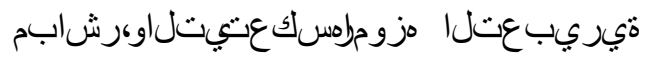




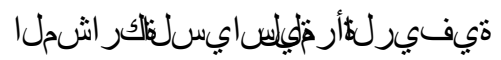

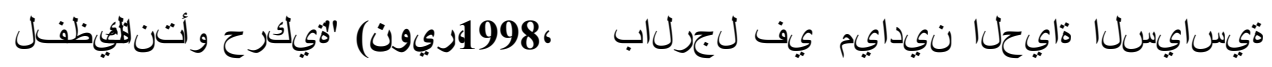
11).

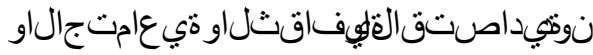

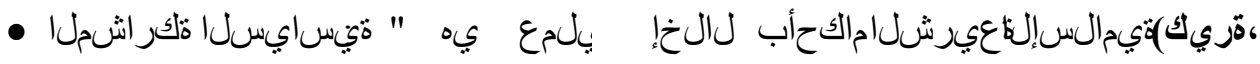

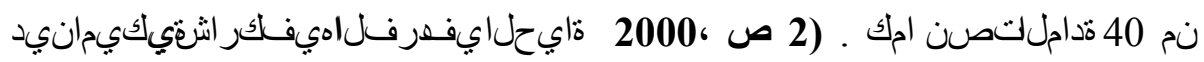

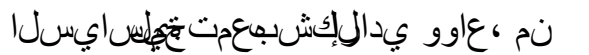

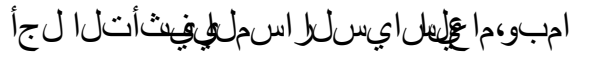

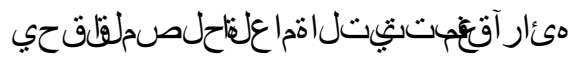

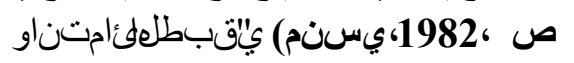
31).

\section{قساردلا ةطخ}

تطخغضومَّقباسلا فـادهأللاجن

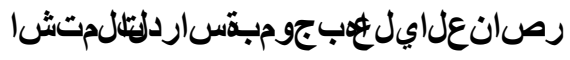
تيناتل

1 - برظنار اطإل

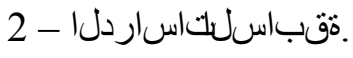

3 - ليلحتلقاقير طوةساردلضضورل

4 - تيث

5 - تساردثاري

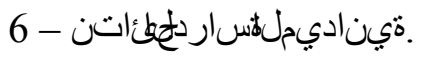

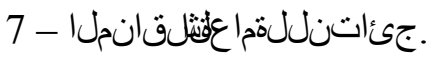

يرظنل - ياراطإل : الوأ

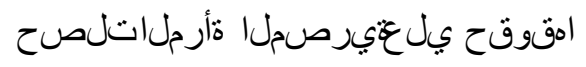

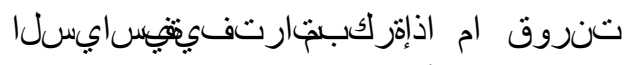

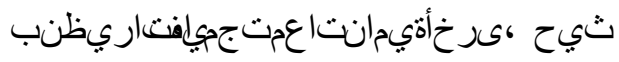

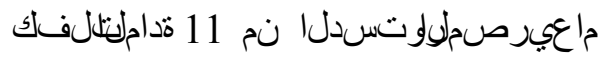

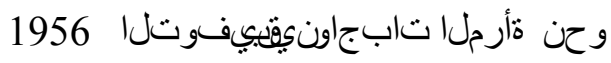

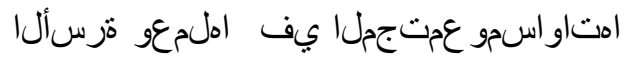

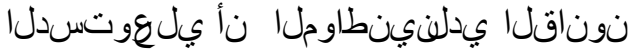

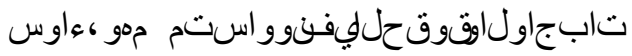

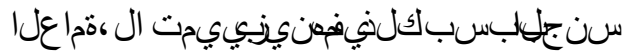

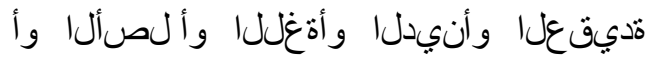

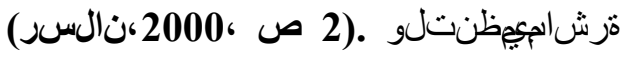

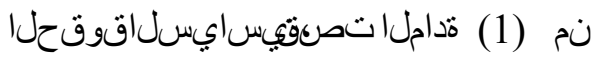

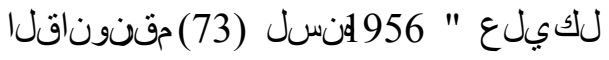

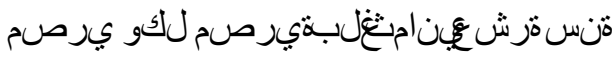

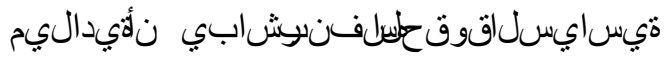

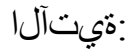

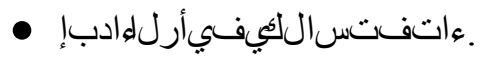

- برجي ثيروهمجلقنلسائرل

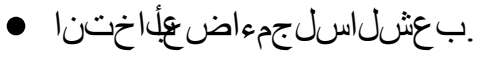
يذلا 1971 ماعُىٔادليلاتسدل

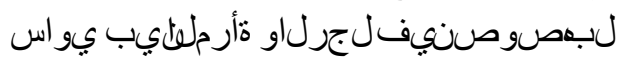

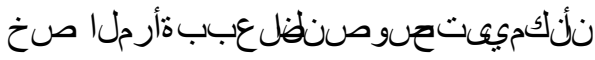

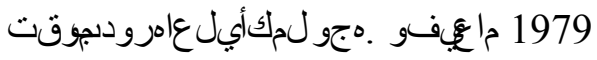
30 3يصنت

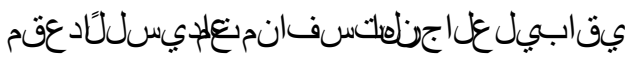

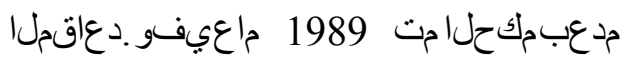

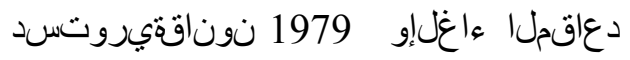

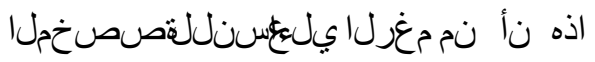

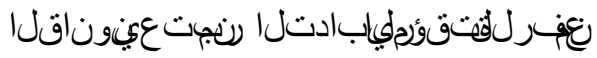

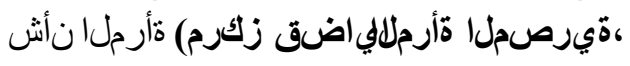
(خيراتن 


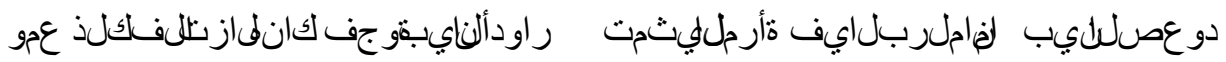

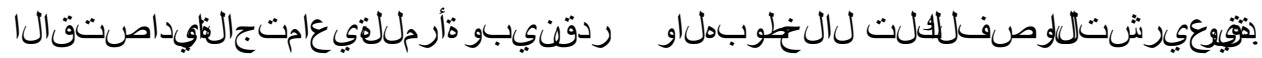

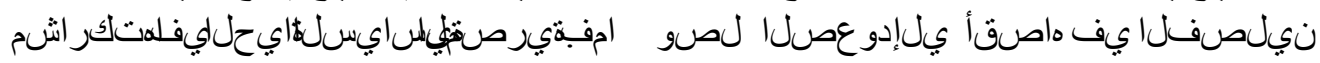

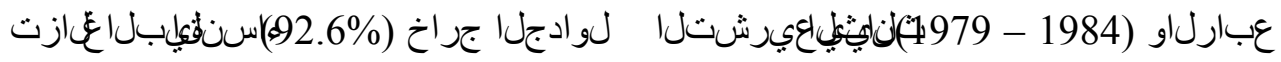

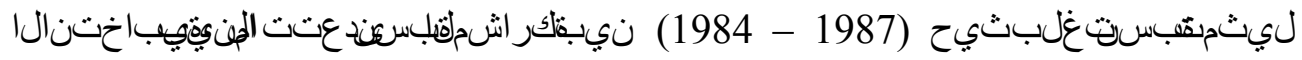

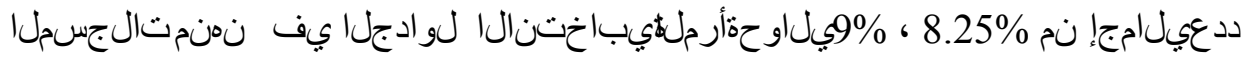

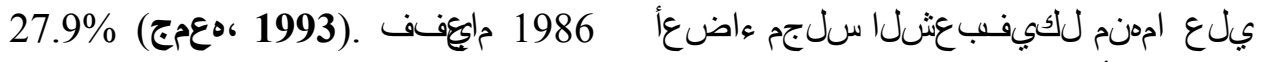

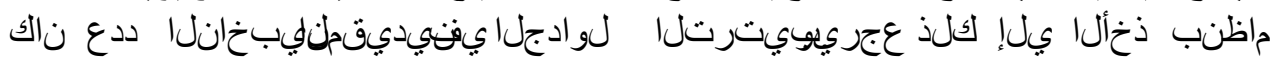

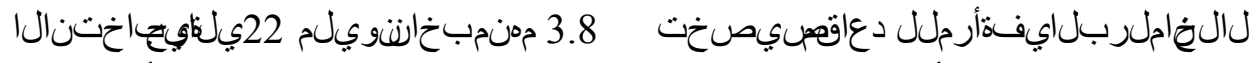

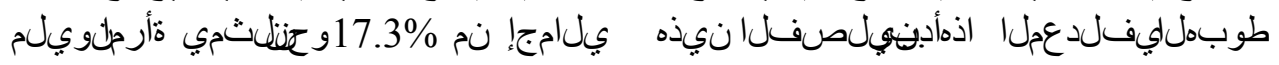

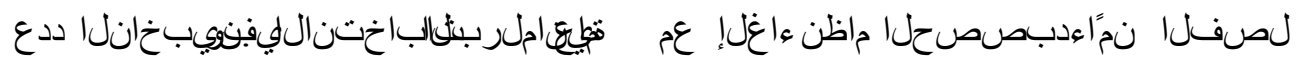

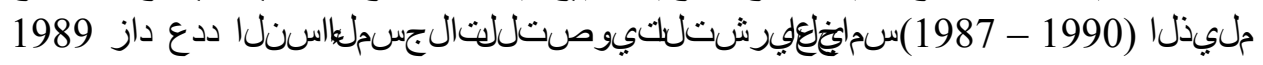

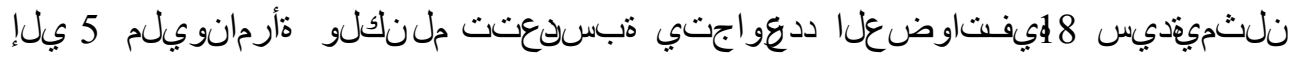

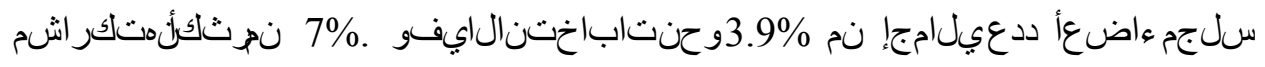

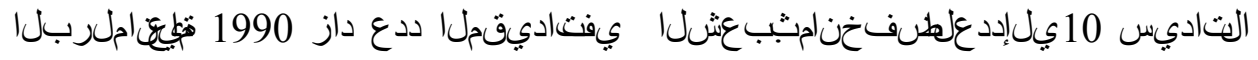

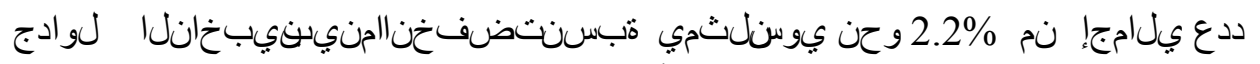

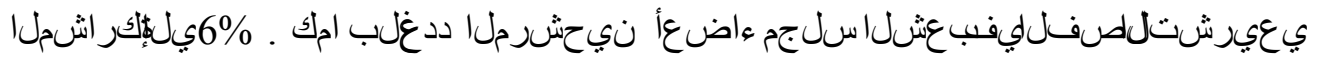

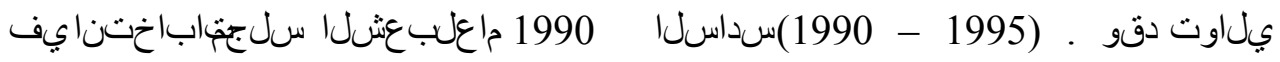

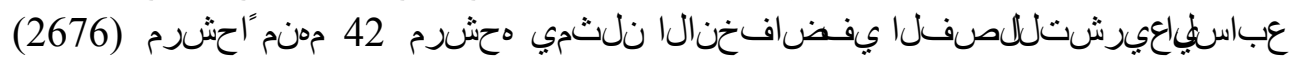

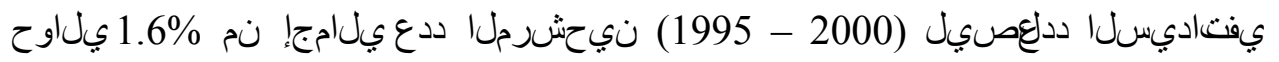

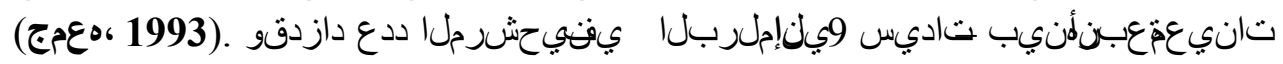

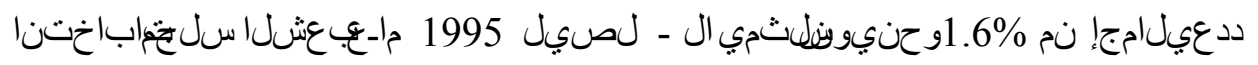

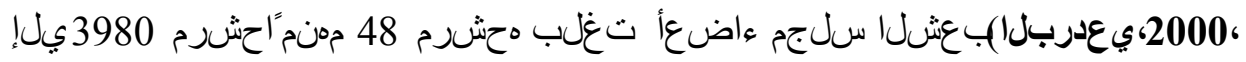

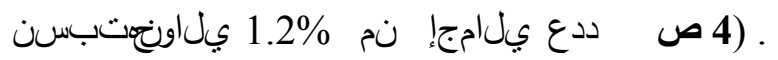

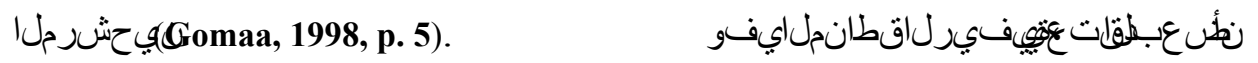

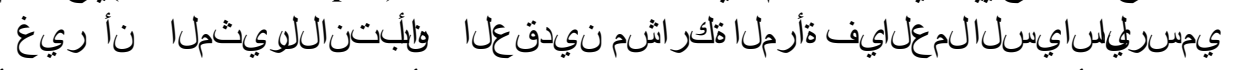

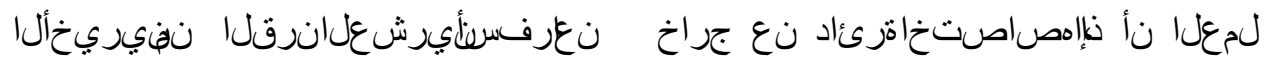

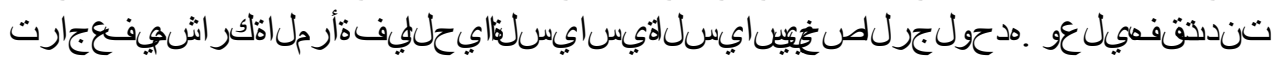

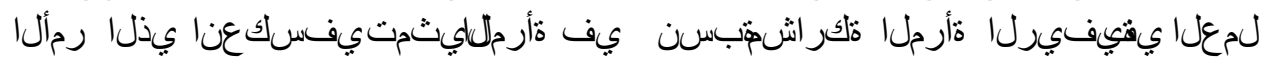

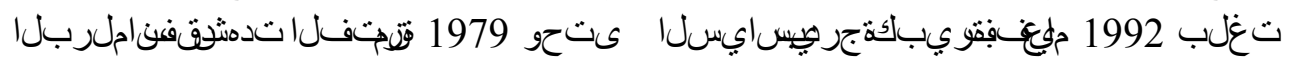

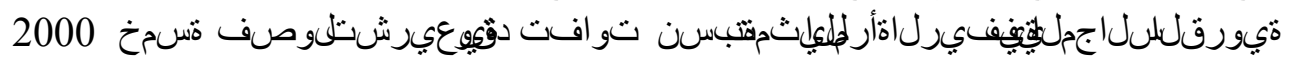




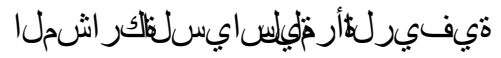

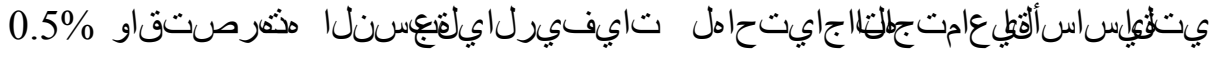

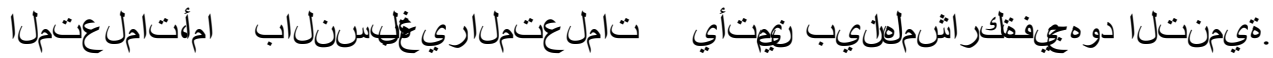

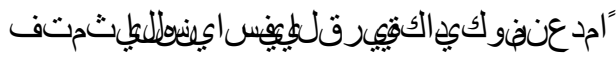

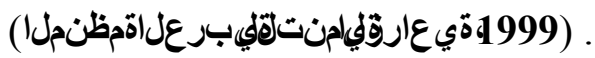

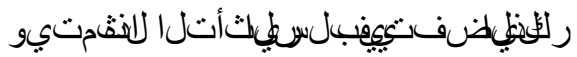

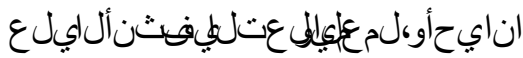

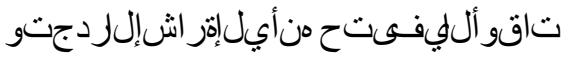

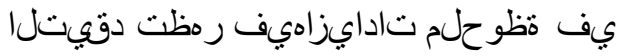

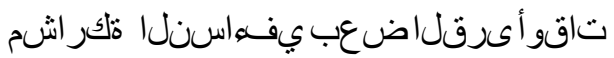

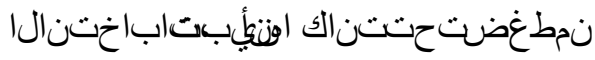

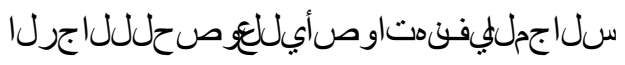

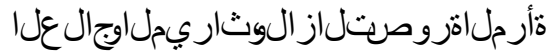

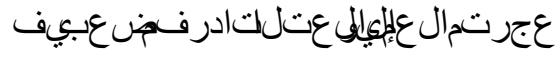

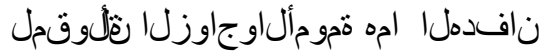

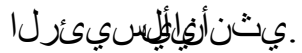

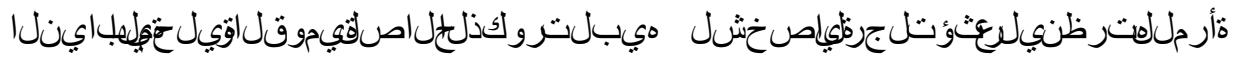

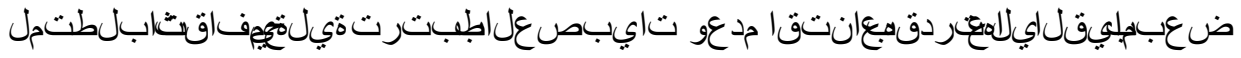

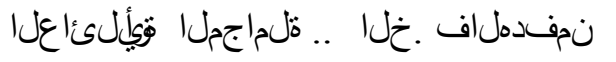

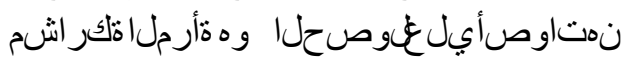

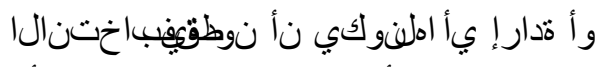

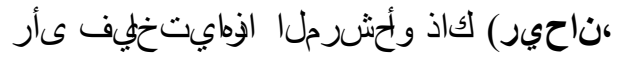
2002، ص5) .

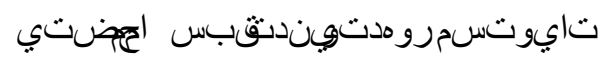

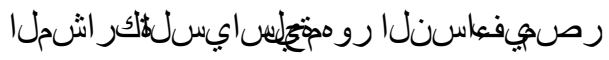

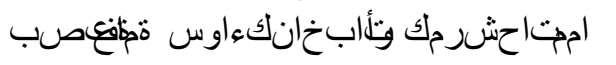

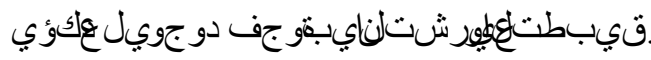

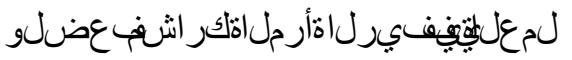

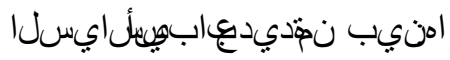

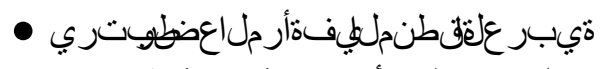

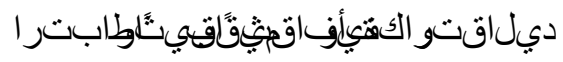

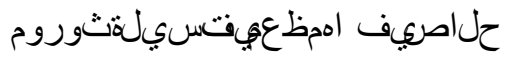

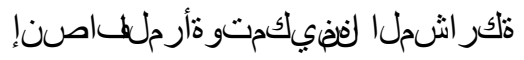

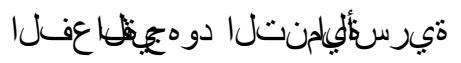

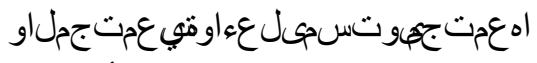

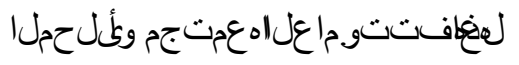

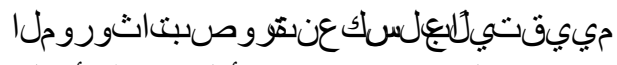

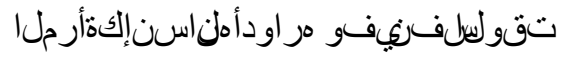

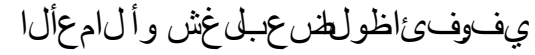

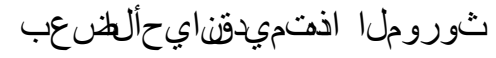

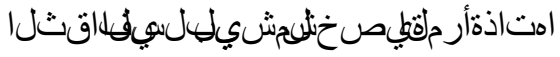

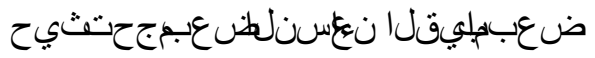

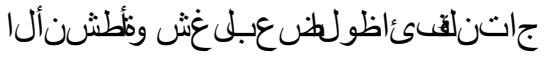

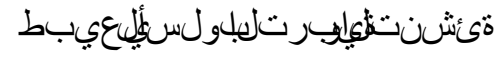

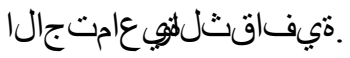

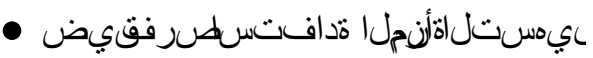

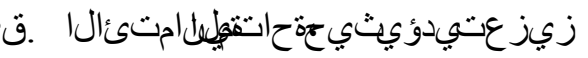

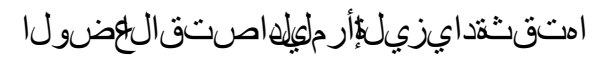

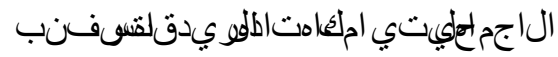

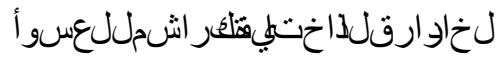

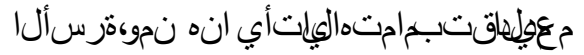

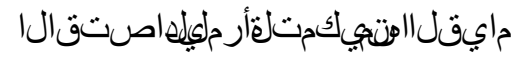

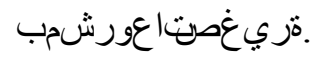

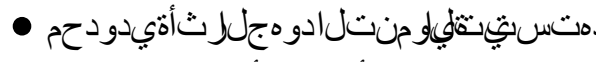

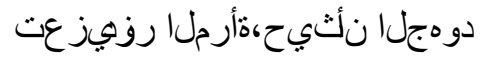

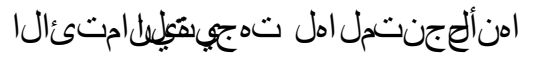

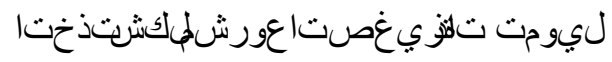

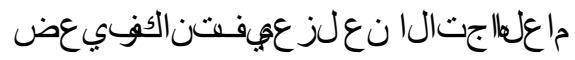




\section{ىبي حن ناحير}

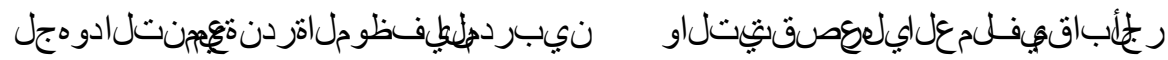

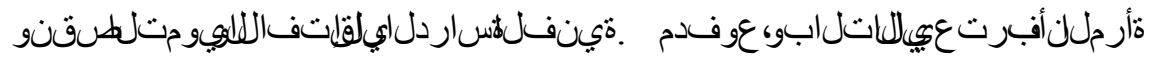

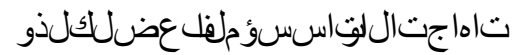

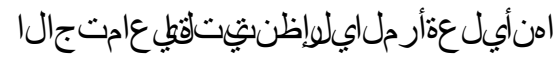

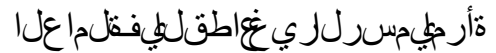

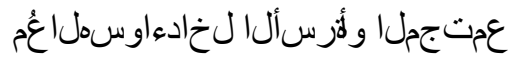

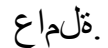

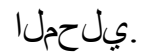

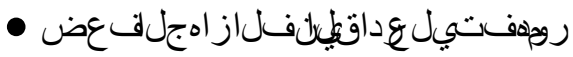

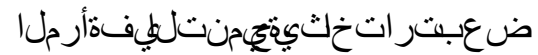

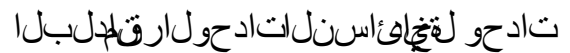

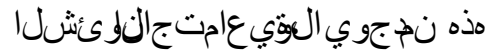

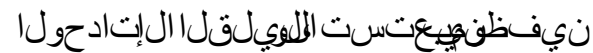

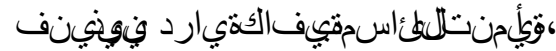

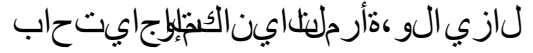

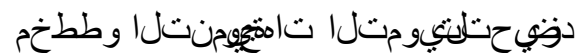
ة قأرملا.

أرملابةصاتثبت امول عملثادعاقلف عض

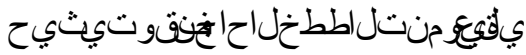

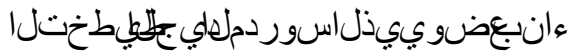

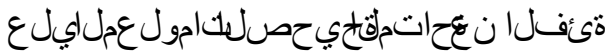

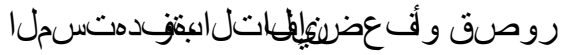

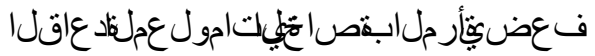

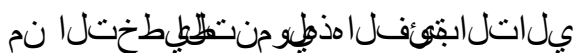

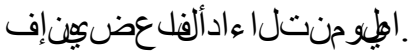

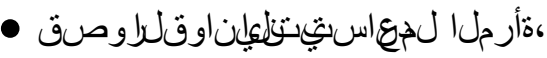

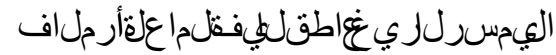

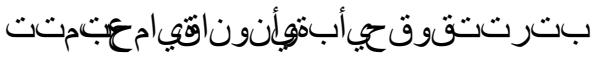

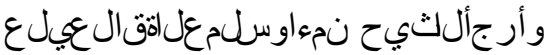

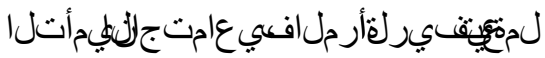
يدقناباقم يأ نودة لعارزلاعاطقيف

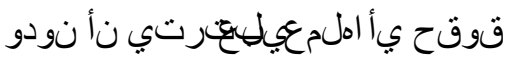

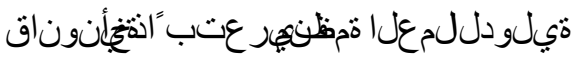

-

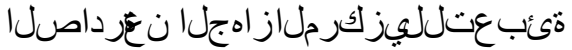

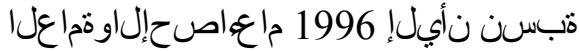

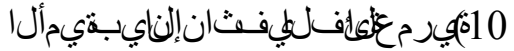
2\% م 50.2\% .

• حالملا نمفلهقوق حبةأرملا ي عوف عض

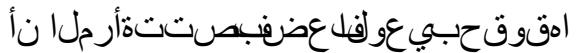

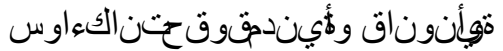

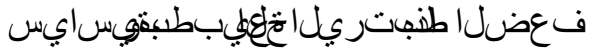

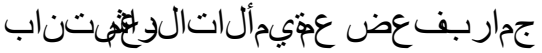

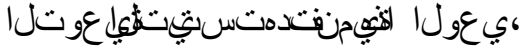

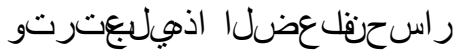

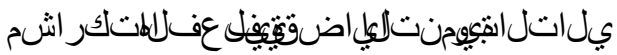

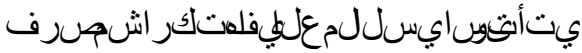

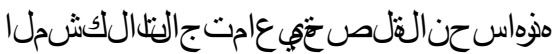

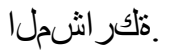

\section{قتقباسلتاساردلًا ائناث}

عالطالحيتأيتل

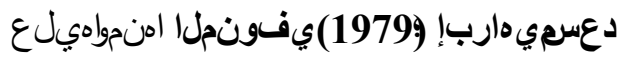
ي-لع ؛ (1986)يفطل ؛ (1981)نيدلإنا

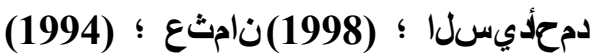

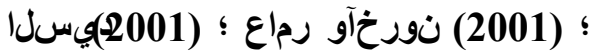

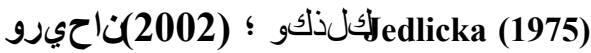

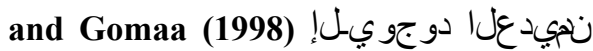

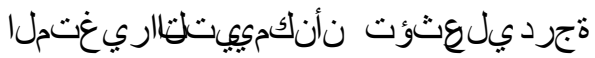

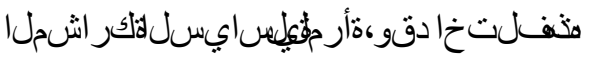




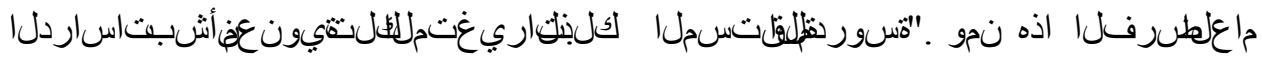

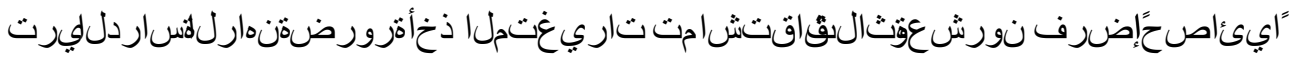

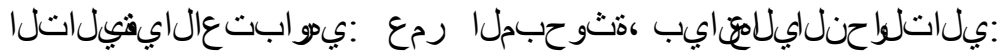

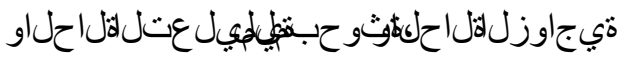

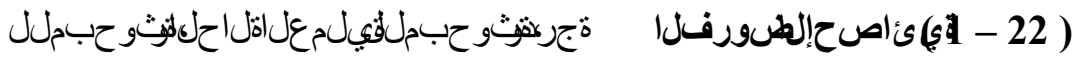

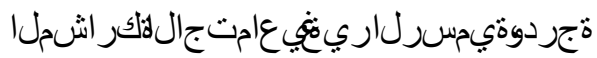

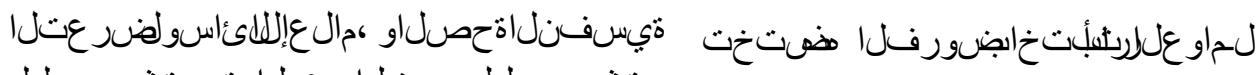

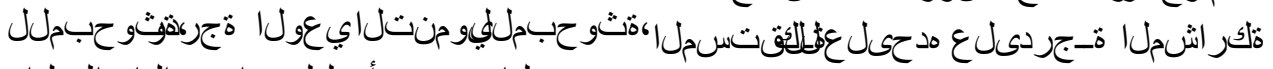

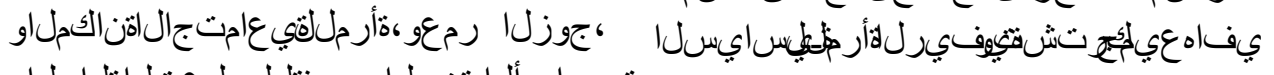

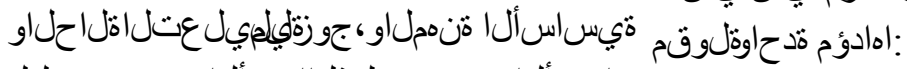

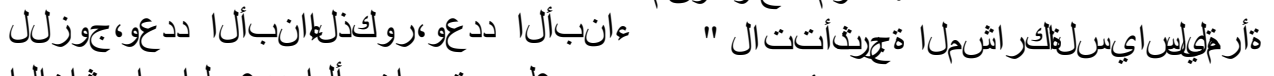

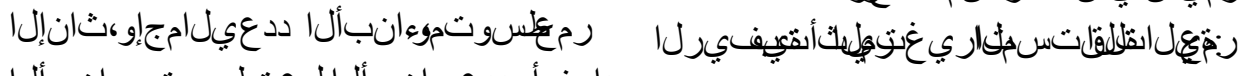

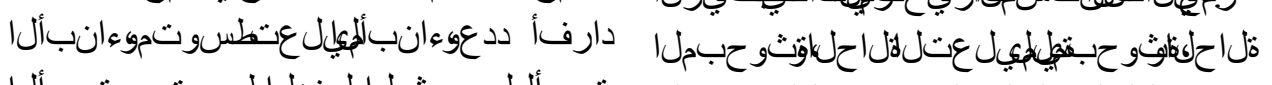

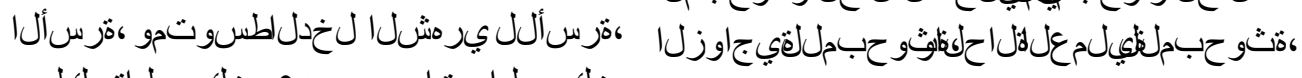

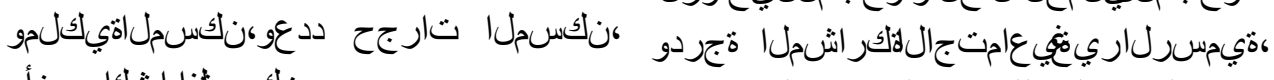
نكسمثلفلاثكاري خأو

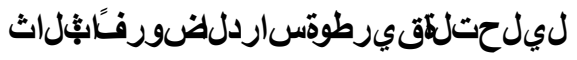

قساردلضلورف - أ

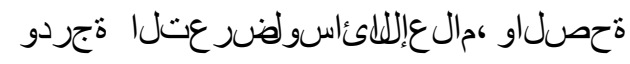

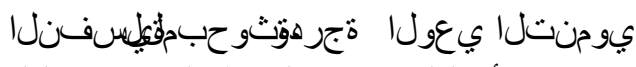

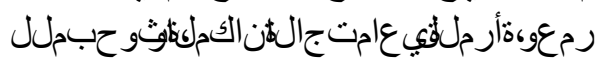

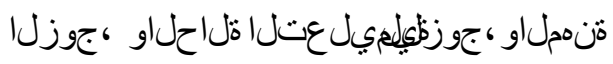

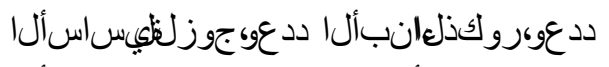

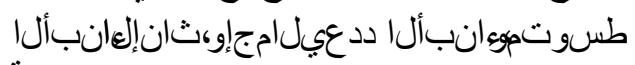

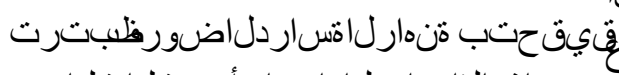

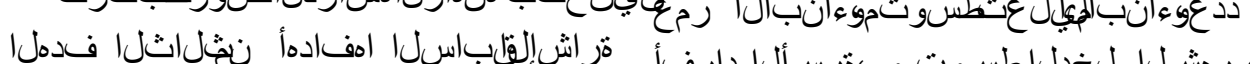

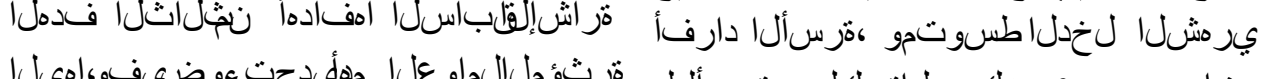

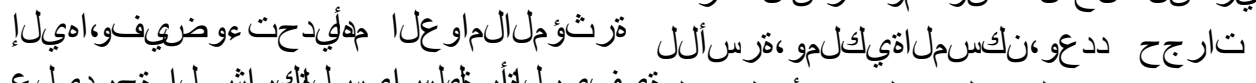

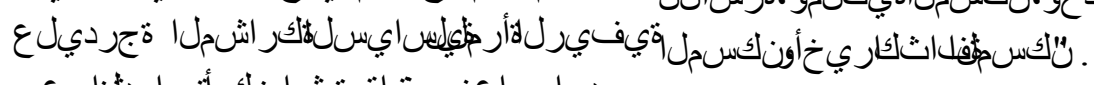

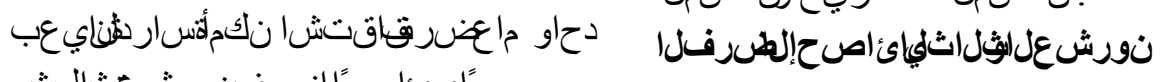

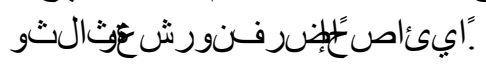

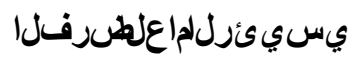

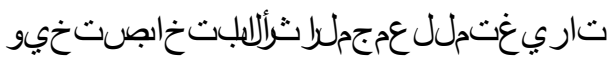

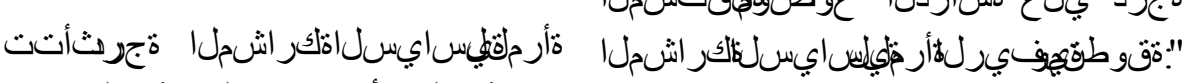

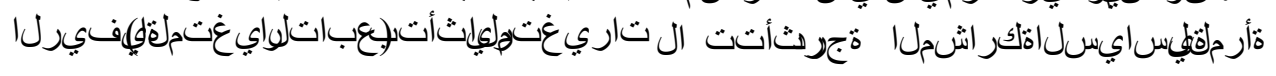


10

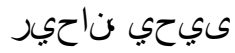

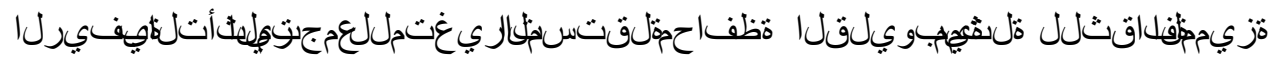
.

لي ل

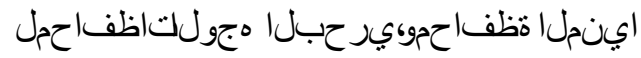

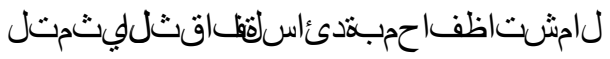

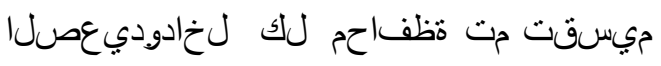

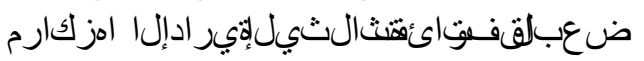

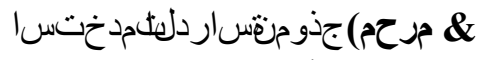

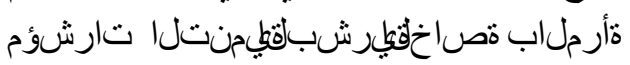

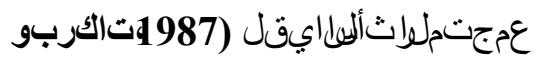

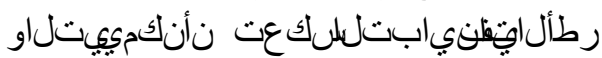
، ، " ل

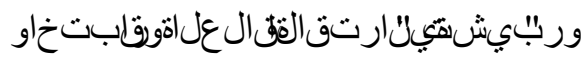

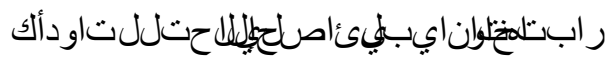
اضلاعورفة الحصنارد.

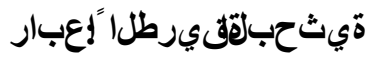

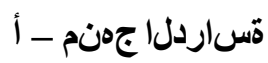

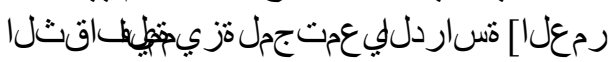

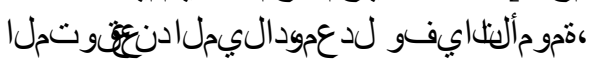

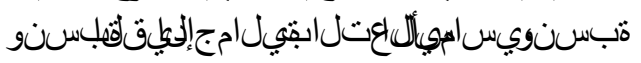

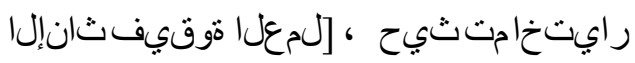

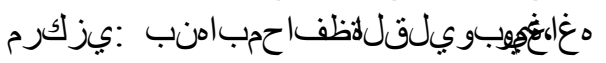

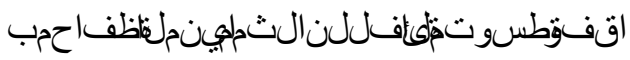

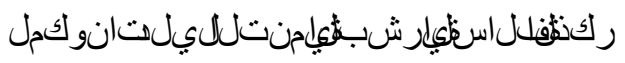

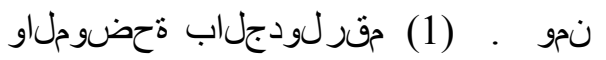

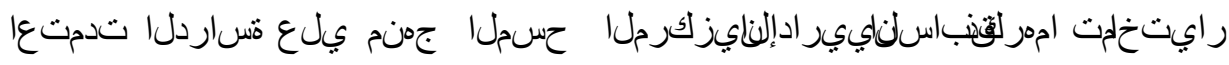

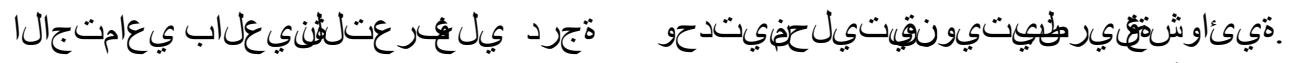

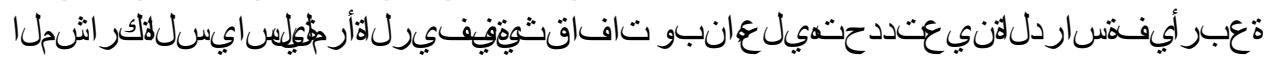

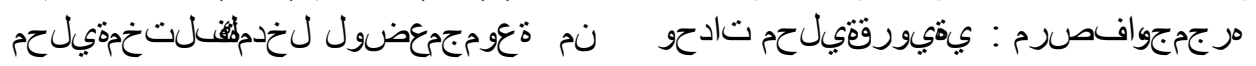

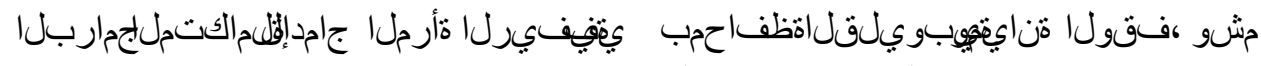

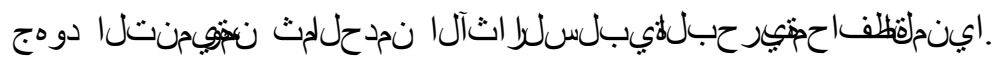

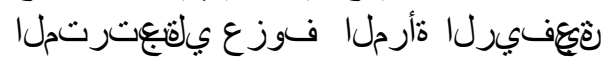

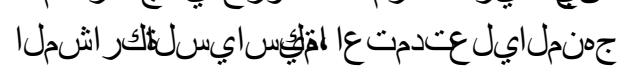

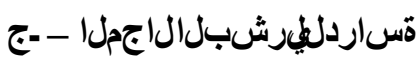

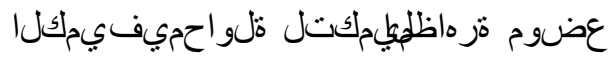

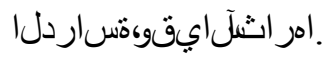

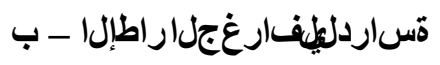

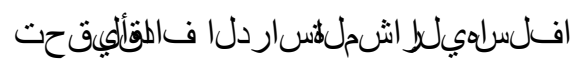

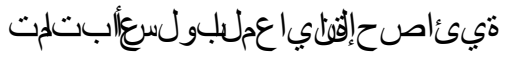

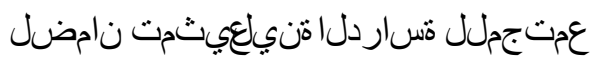

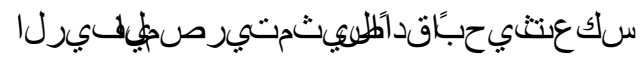

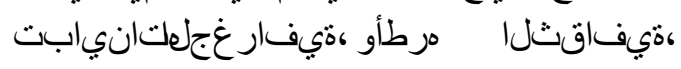

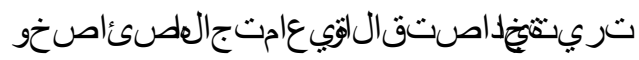

Arab Univ. J. Agric. Sci., 13(1), 2005 
تيفير لهأرتليليسايسلكالكر اشمل

Arab Univ. J. Agric. Sci., 13(1), 2005 


\section{ىبي ناحير}

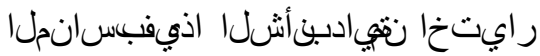

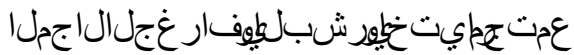

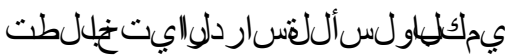

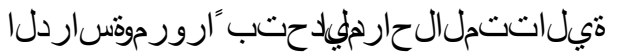

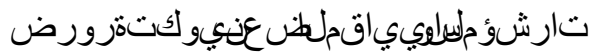

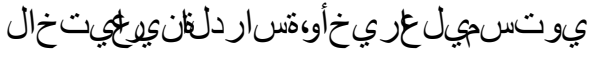

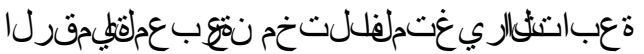

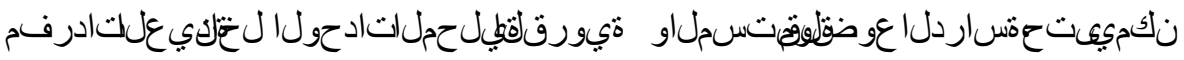

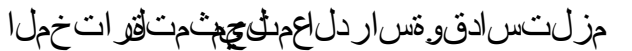

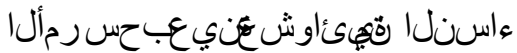

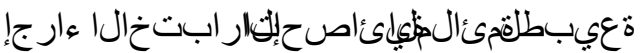

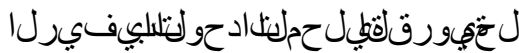

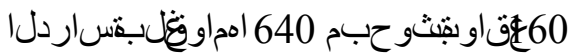

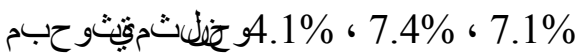

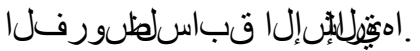

عرقبوسألا ددعيلامجإ نم 10.3\% ، 10.3\% ،

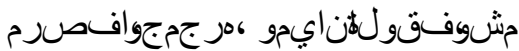

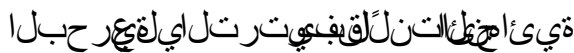

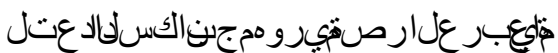
1996 .

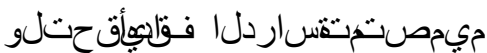

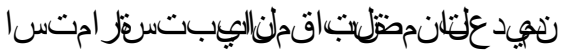

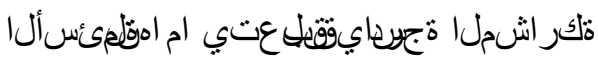

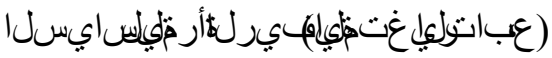

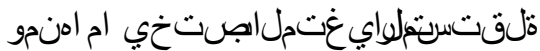

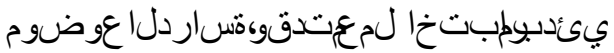

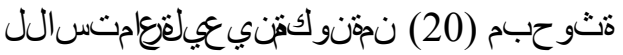

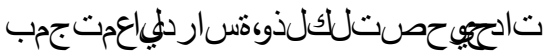

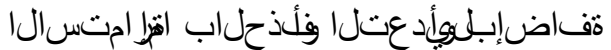

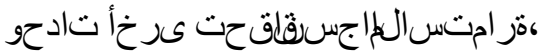

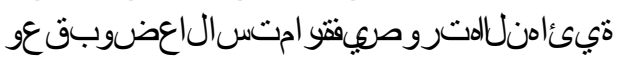

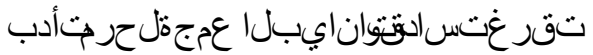

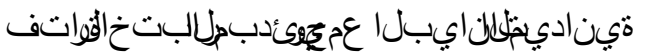

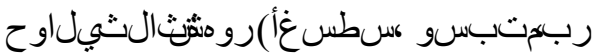

2003 .

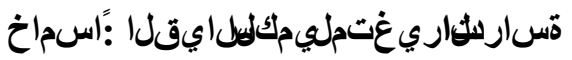

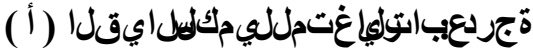

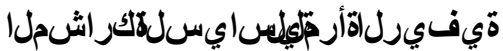

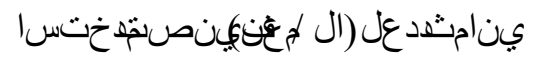

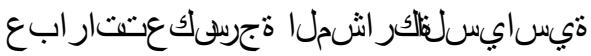

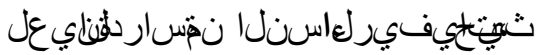

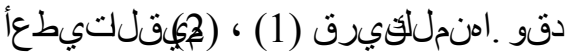

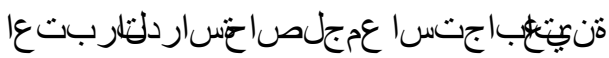

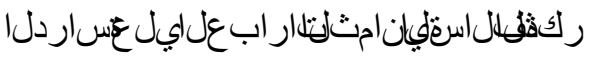

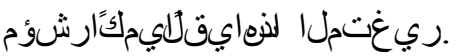

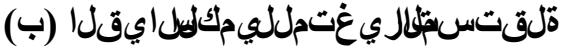

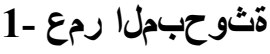

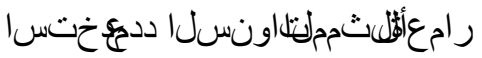

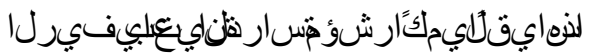

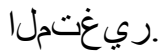

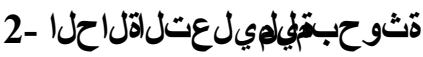

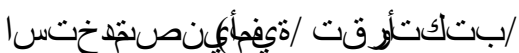

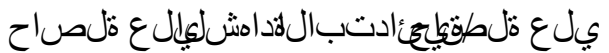

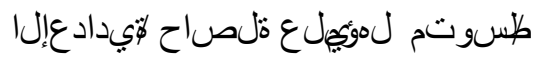

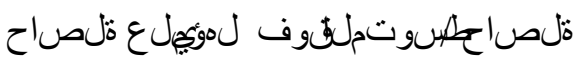
، 


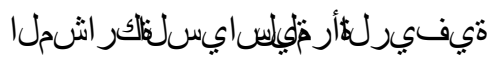

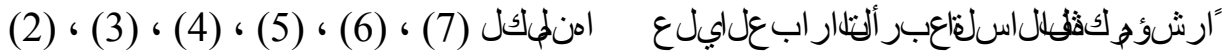

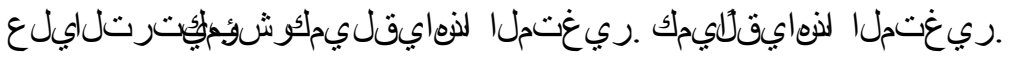

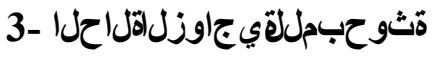

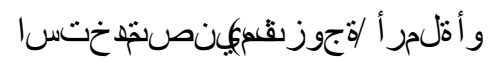

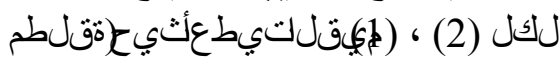

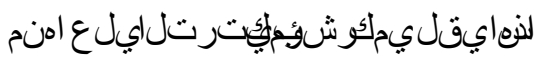

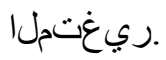

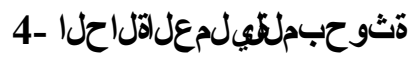

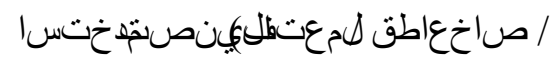

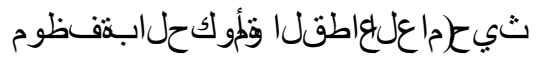

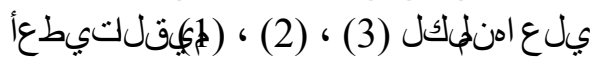

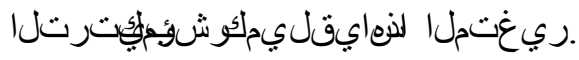

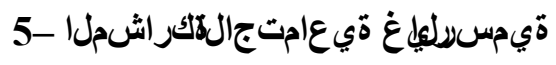

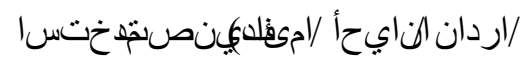

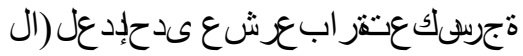

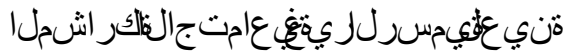

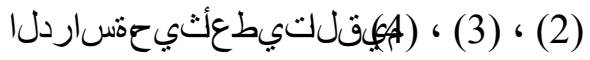

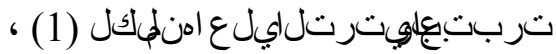

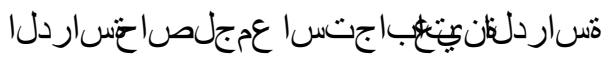

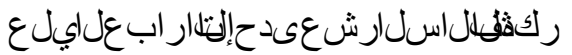

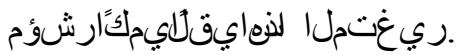

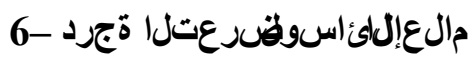

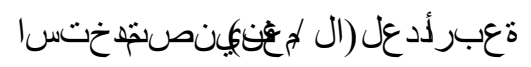

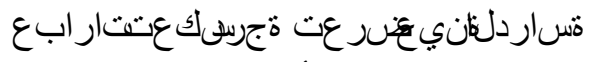

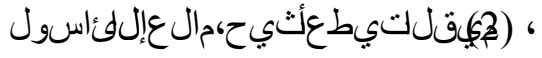

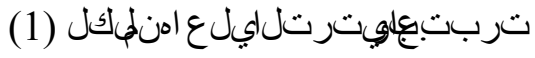

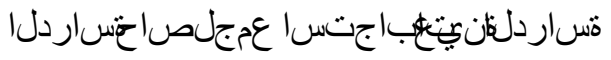

\section{تثو حبتهيليسفنلةحصلا -7}

/ ام دحيلإ التديفعيكينصنته ختسا

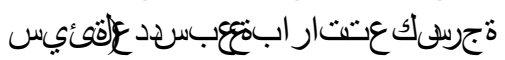

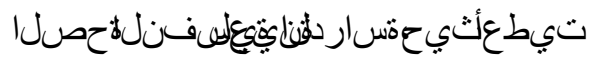

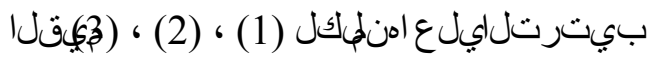

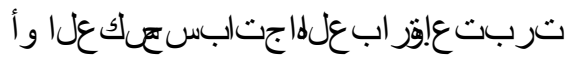

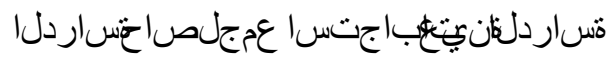

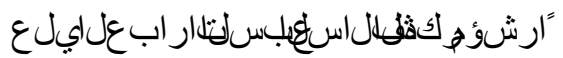

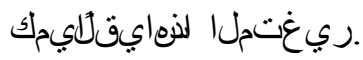

\section{تثوحبملنيومنتلاي عولا ةجرد -8}

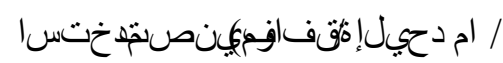

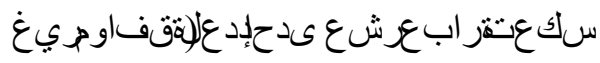

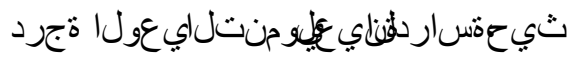

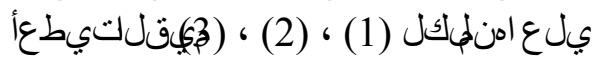

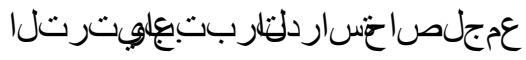

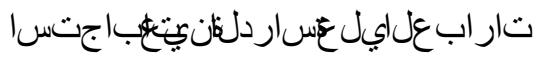

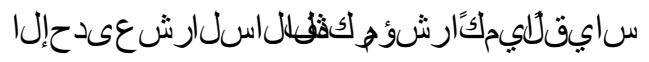

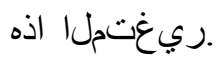

\section{قأرملل قي عامت جالةن(كملا -9}

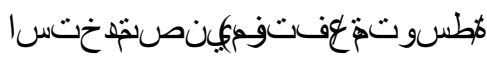

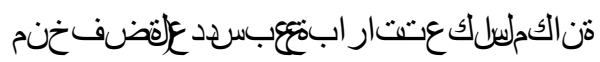

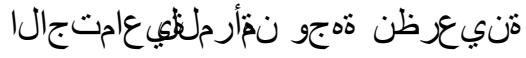

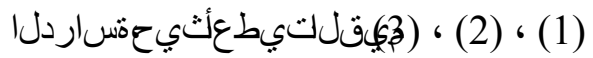

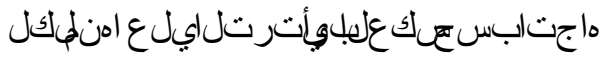

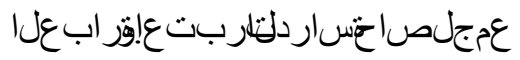




\section{ىبي حناحير}

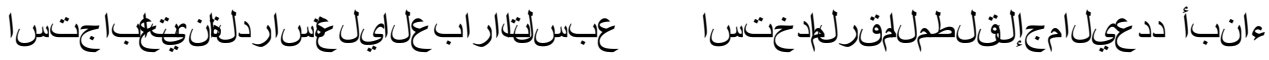

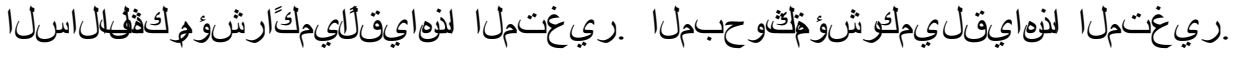

جوزلا رمع -10

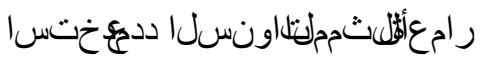

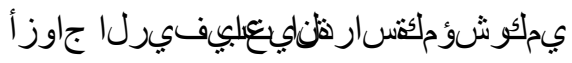

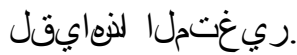

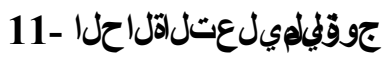

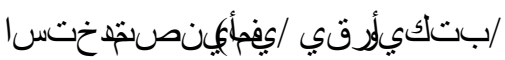

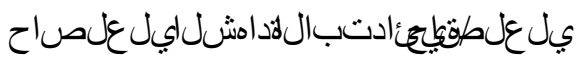

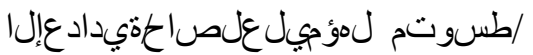

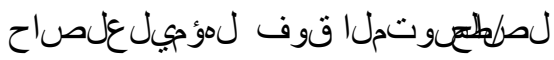

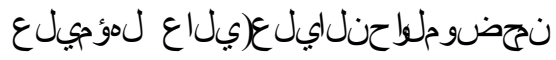

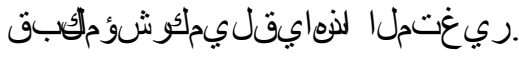

\section{جوزلا قنهم -12}

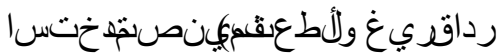

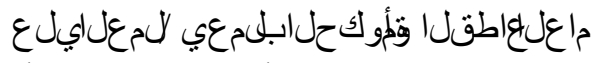

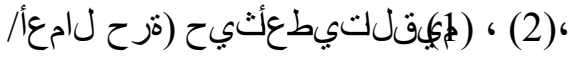

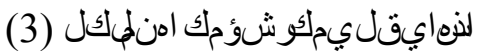

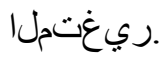

\section{روكذكعانبأل دا ددع -13}

روكذلكانبأل ادد علقلطحللجقرلعادختسا

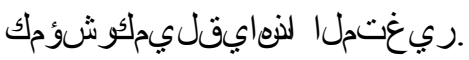

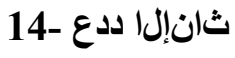

ثان إلعانب أل اددعلقلطمللمقرلعادختسا

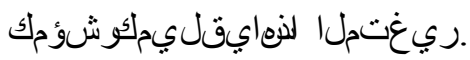

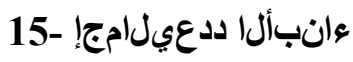

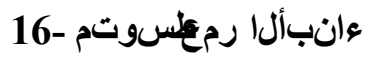

$$
\text { تاونسلابهانبألا رمعطسوتمدختسا }
$$

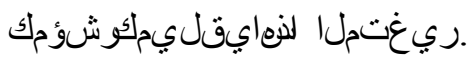

\section{عانبألميال عنطسوتم -17}

\section{ءانبأليال عت ةترطسوتشخ ختسا}

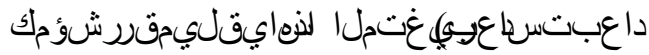

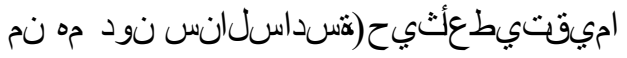

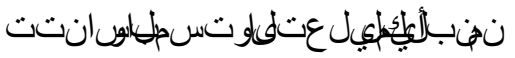

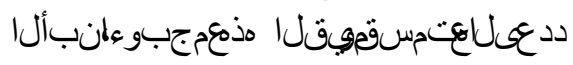

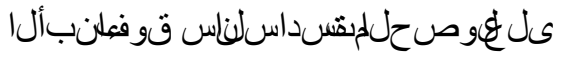

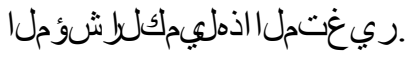

قرسألدارفأ ددع -18

نكسنبيجميقجلةرسألدارفأ ددمئخسا

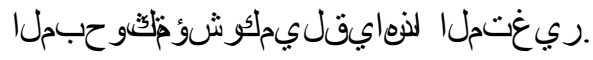

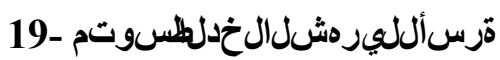

$$
\text { ةرسألكير مشل خدلطسو تمخ ختسا }
$$

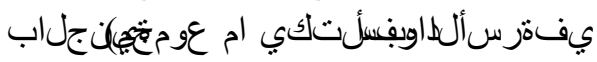

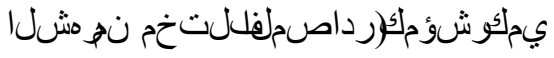
ريغترل

\section{نكسملكيكلم -}

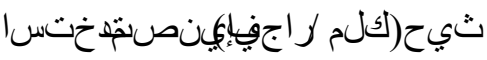

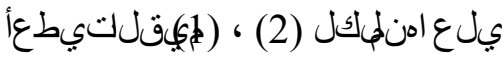

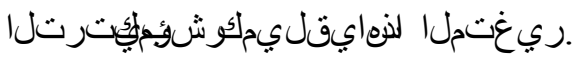

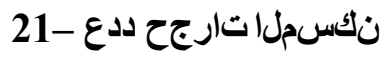




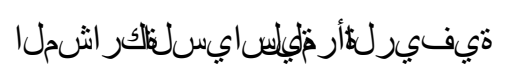

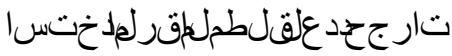

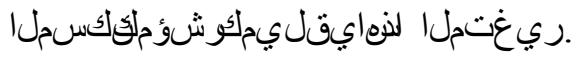

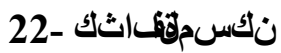

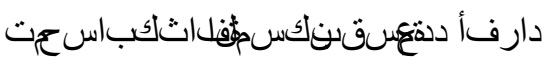

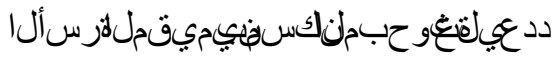

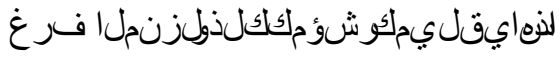

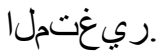

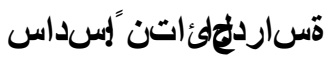

لوأل|فدهل

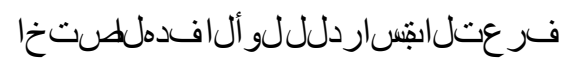
تايفيرقليليسايسلقالكر اشملا ةتجرديل

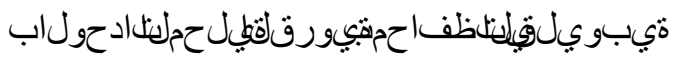

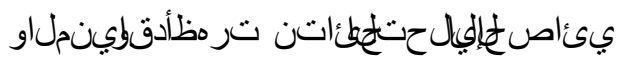

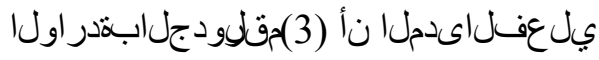

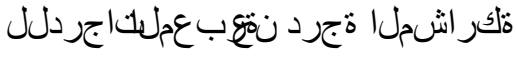

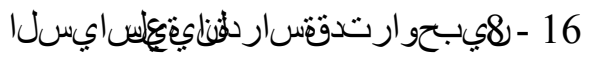

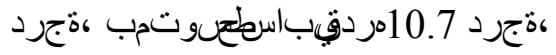
ميسقتبو .ةجرد 3.20ردقير اي عرف اردار حناو

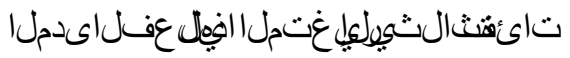

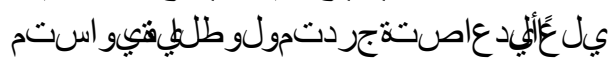

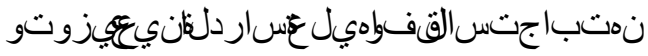

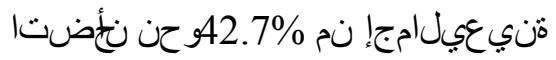

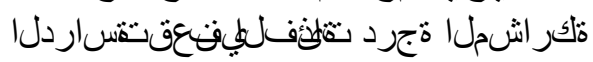

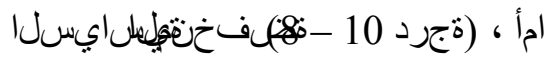

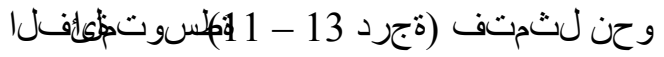

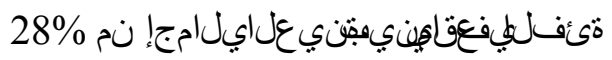

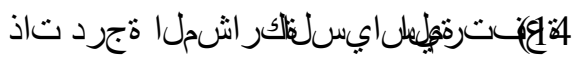
ة ننيعيلامجا نم 29.4\% حن (ةتجرد 16 قنساردلا.

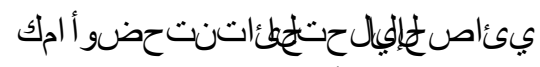

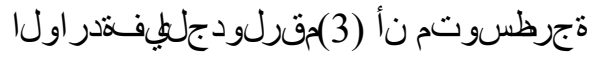

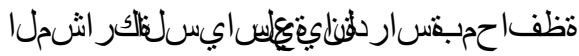

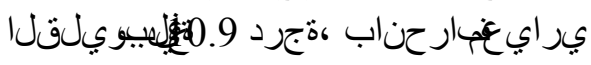

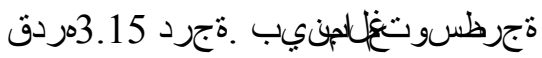

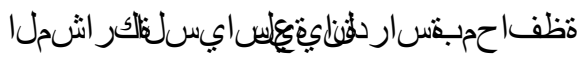

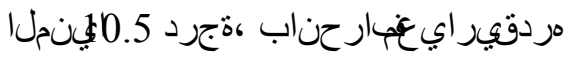
نجرد يناثلرافدهل 


\section{ىي حي ناحير}

ةجرفالتخا ىدميفهج عتل

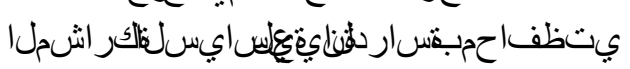

ثلاثل|فدهل

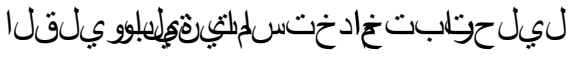

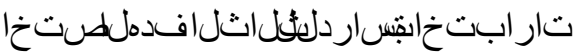

ليلحتخجئاتن

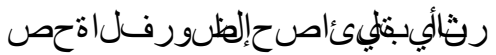

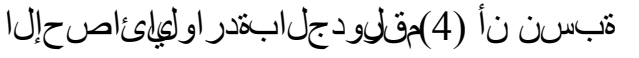

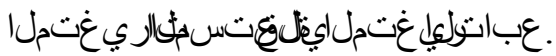

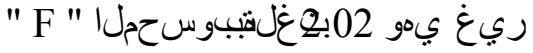

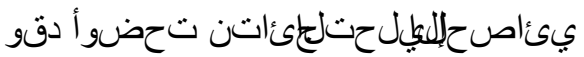

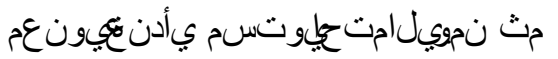

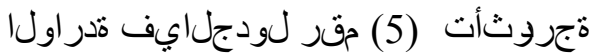

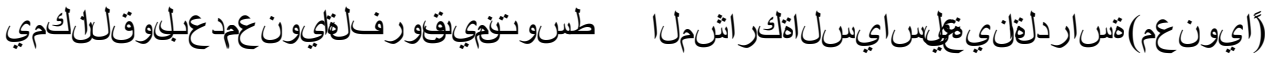

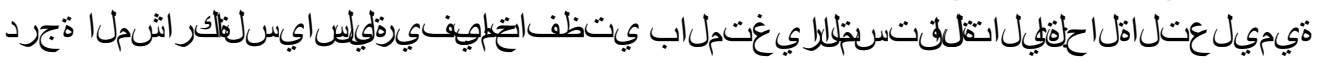

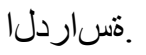




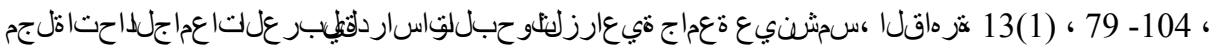
2005

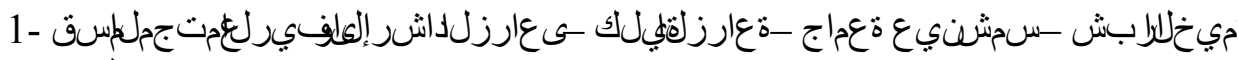

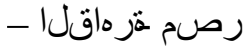

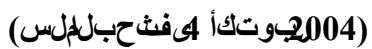

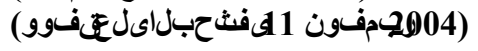


ىي ين ناحير

Arab Univ. J. Agric. Sci., 13(1), 2005 
19

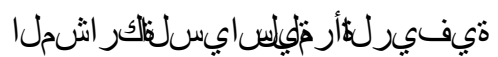

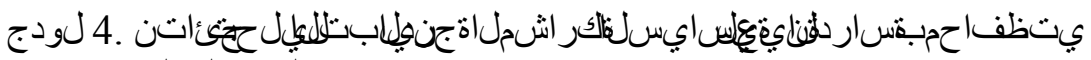

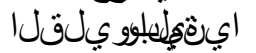

\begin{tabular}{|c|c|c|c|c|}
\hline نيابتل اردصم & 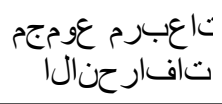 & تير حلان & تافبرارحنسوتالم & ب" \\
\hline تاعومججنايب & 20.66 & 1 & 20.66 & 2.02 \\
\hline تاعومجمل الخاد & 6538.46 & 638 & 10.25 & \\
\hline يلالجيابتال & 6559.12 & 639 & & \\
\hline
\end{tabular}

قيناديملةساردلا ردصمل|

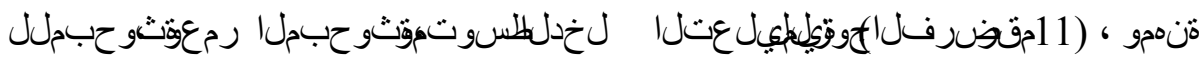

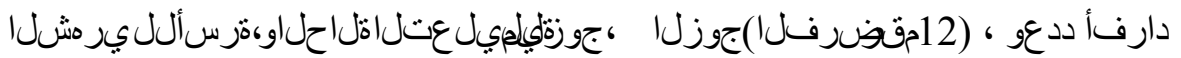

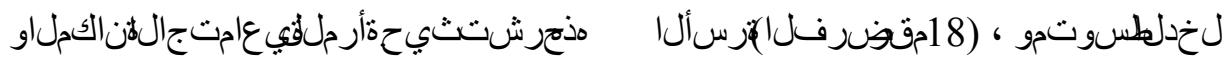

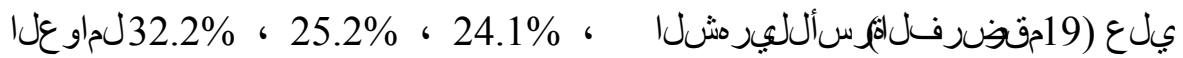

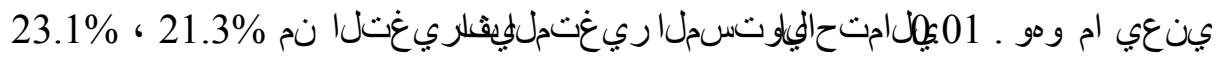

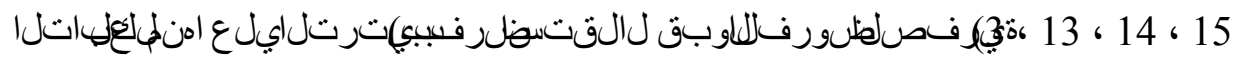

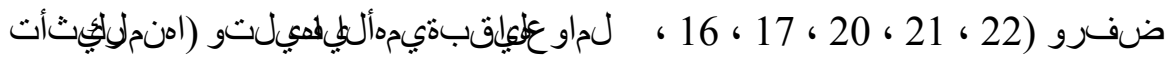
.

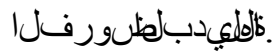

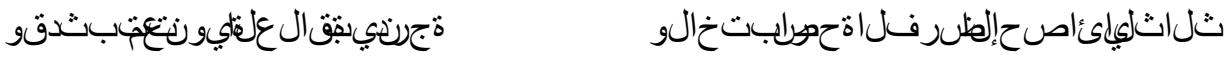

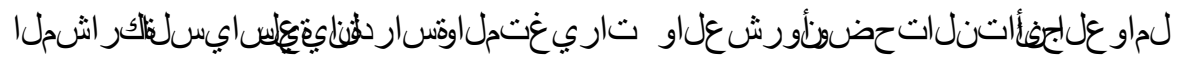

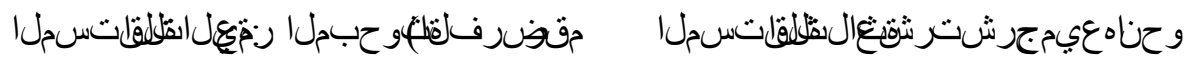

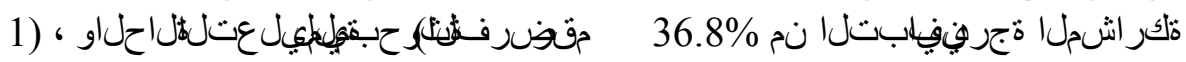

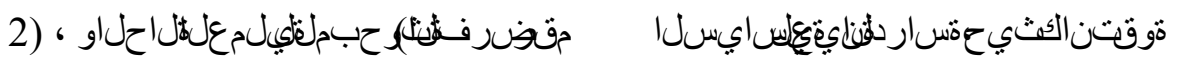

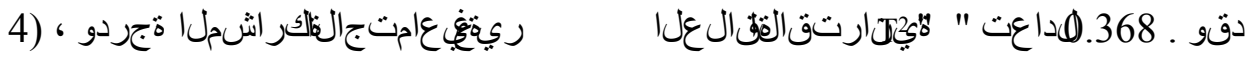

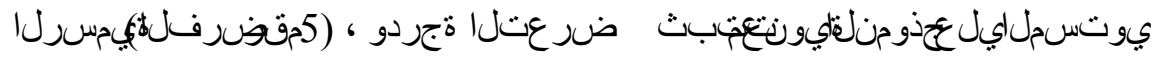

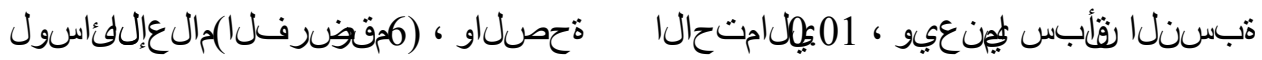

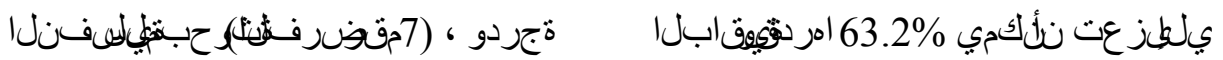

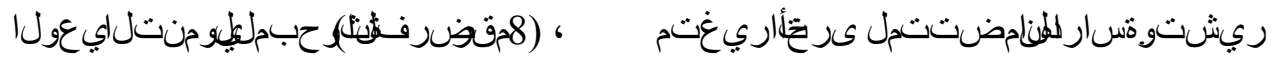

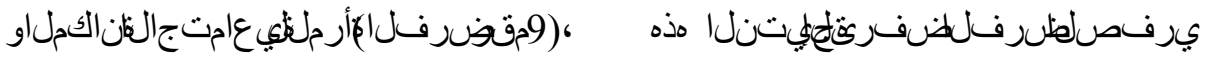

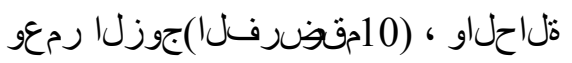




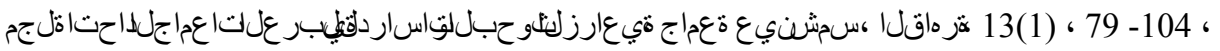
2005

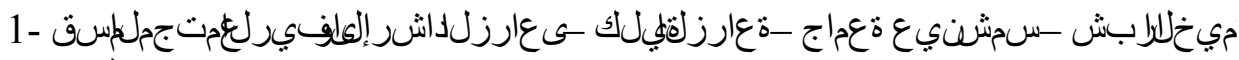

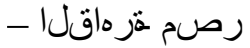

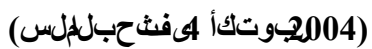

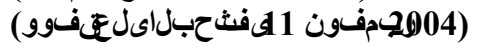


تيفيرلكأرثليلسيسايسلطاكر اشمل

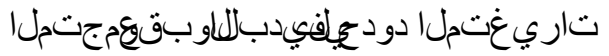

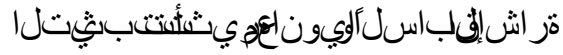
اهيل إنبال.

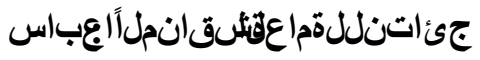

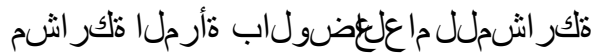

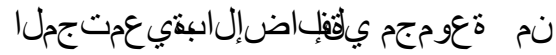

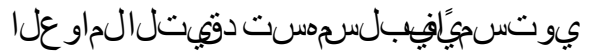

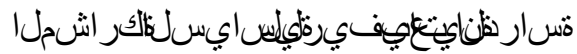
:

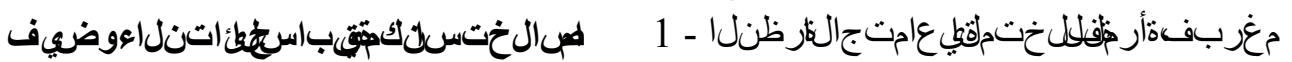
ينلي

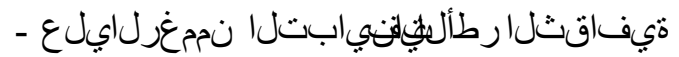

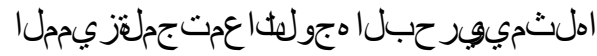

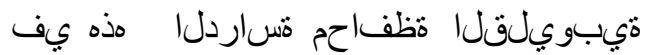

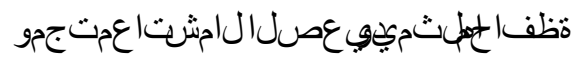

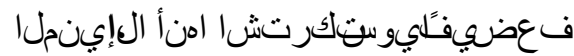

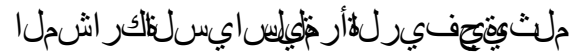

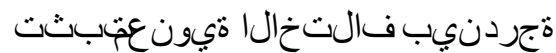

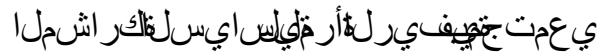

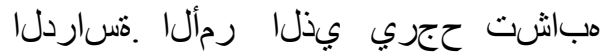

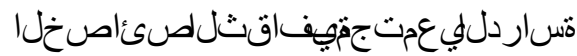

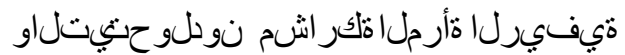

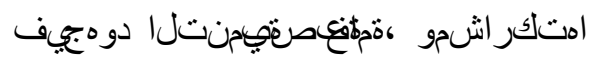

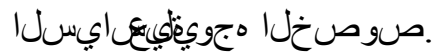

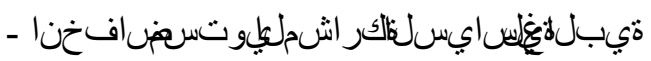

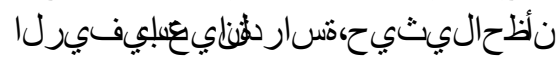

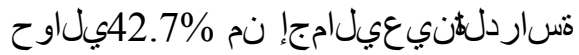

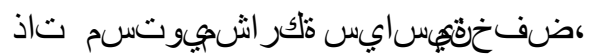

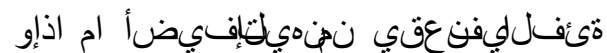

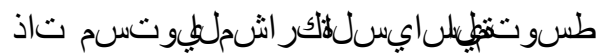
نم

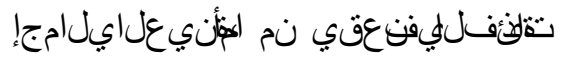

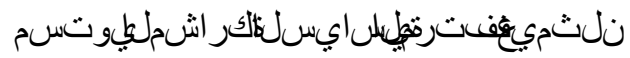
تساردلةنيع ريلامجإ نم 29.4\%وحن

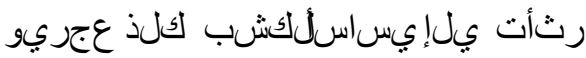

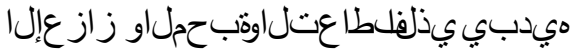

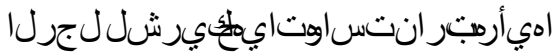

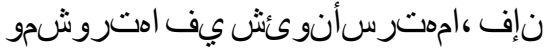

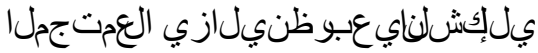

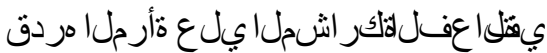
ثأرملا نأُغربفقتيسايسل

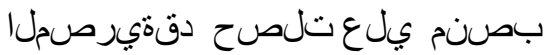

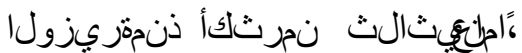

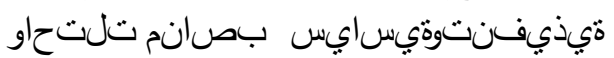

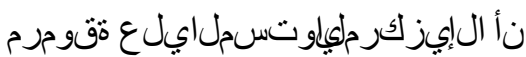

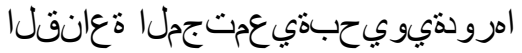

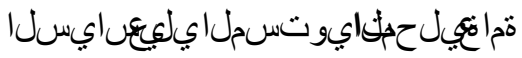

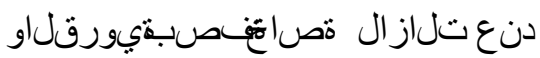

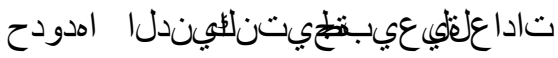

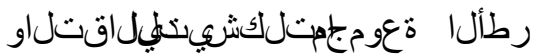
نأ الولو. فظف أثيلفل 1976 مائيلحملالمك حلنوناقضرف

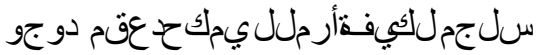

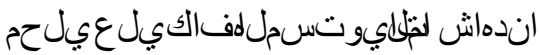

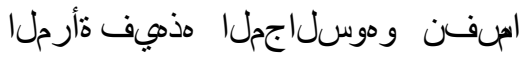

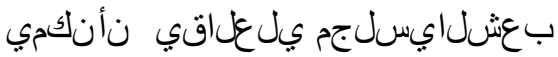

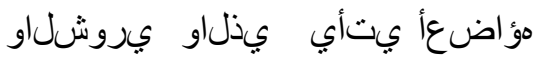

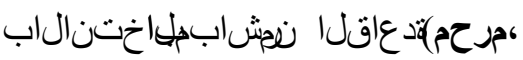

1990، 174) . 


\section{ىب حي ناحير}

صاخلاقباسلاس لماعلبلستكا اجبرو

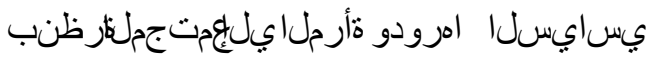

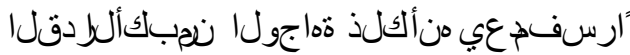

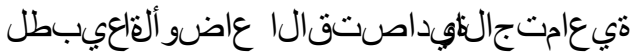

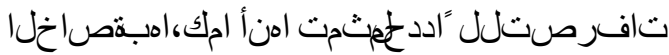

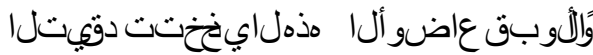

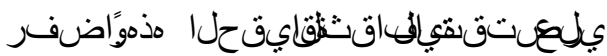

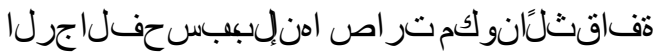

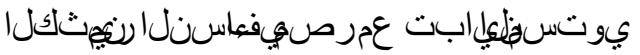

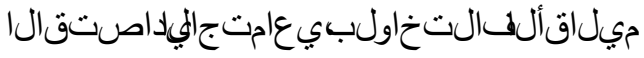

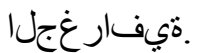

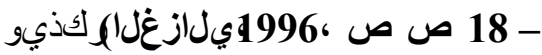

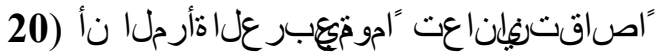

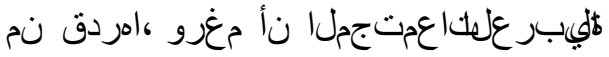

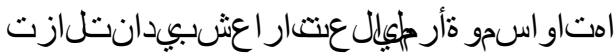

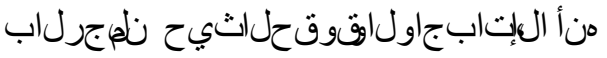

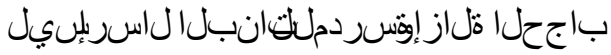

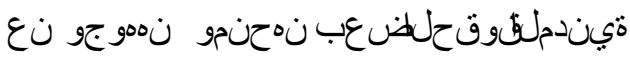

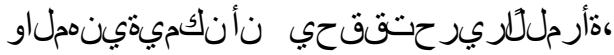

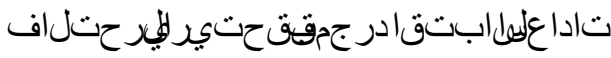

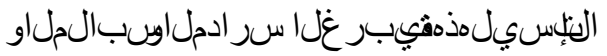

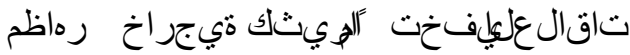

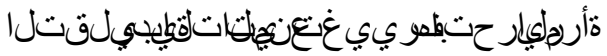

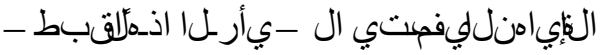

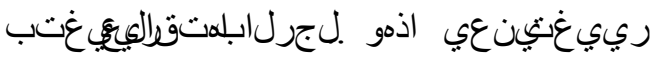

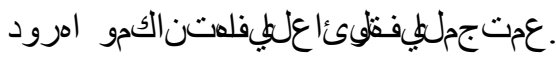

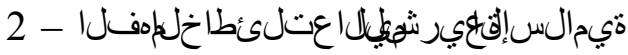

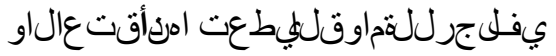

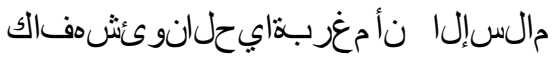

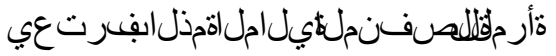

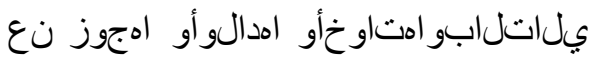

فرصتلاو اهلاومأ ثرادإ قعبيطعي

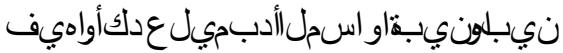

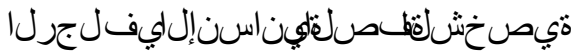

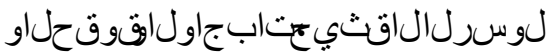

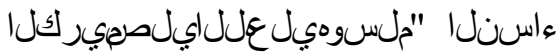

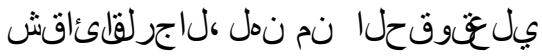

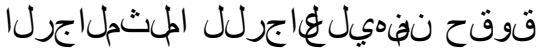

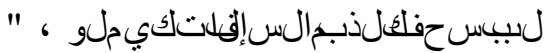

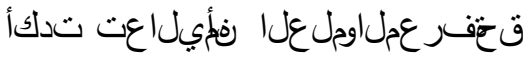

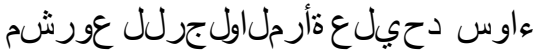

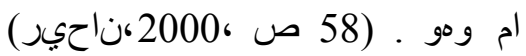

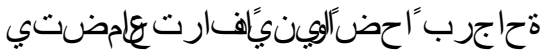

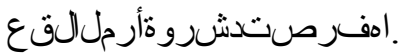

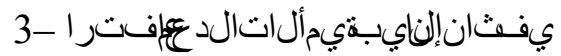

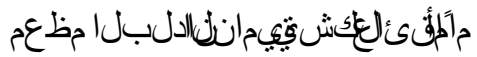

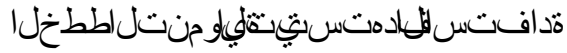

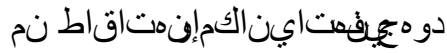

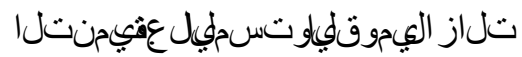

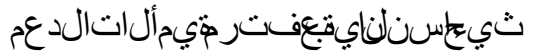

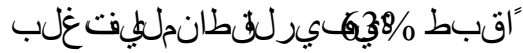

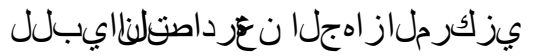

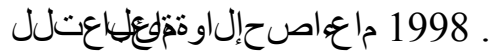

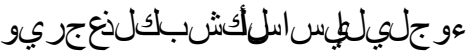

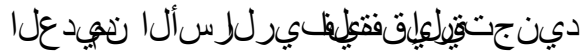

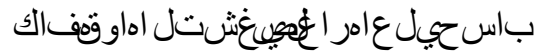

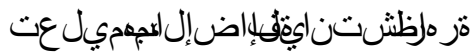

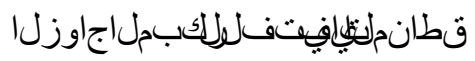

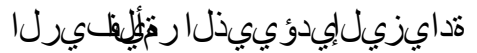

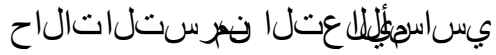

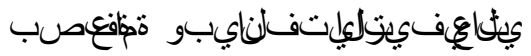

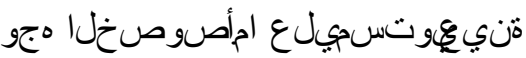




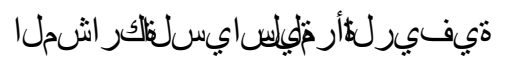

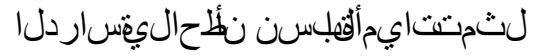

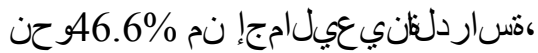

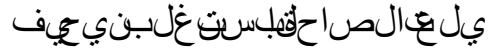

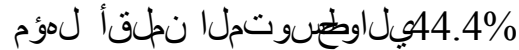
وطسوتم لـؤميلغوالصالحل

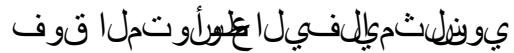

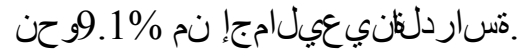

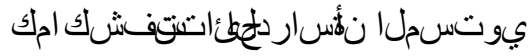

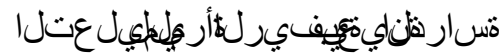

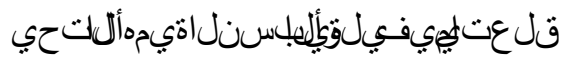

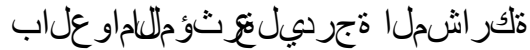
نم 32.2\% حنحشيثرية تحسايسل

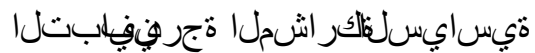
فساردلثنابعل

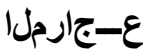

قيبرعلاعجارملا : الوأ

"ريمنتل" . (1981)نيدلدعسهميهاربإ

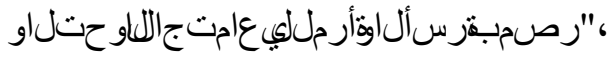

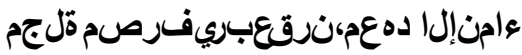

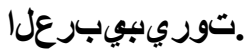
تأرمل امجيلئيقت .

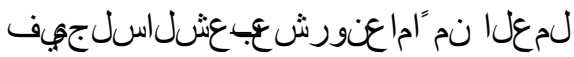

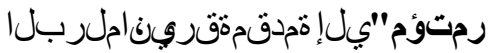

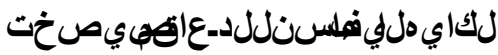

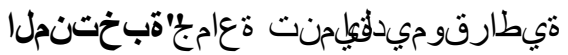

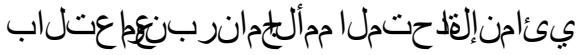

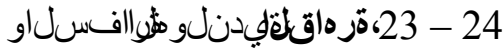
.

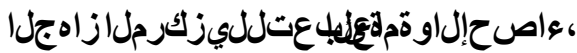

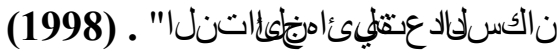

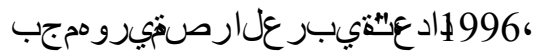

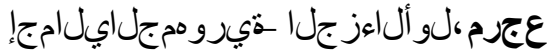

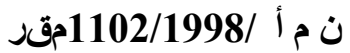

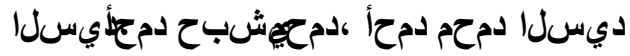

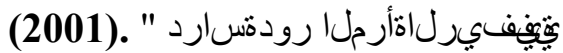

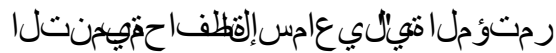

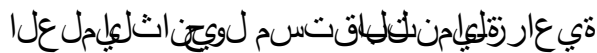

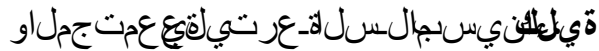

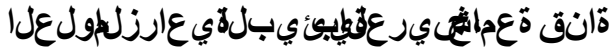

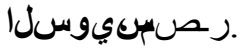

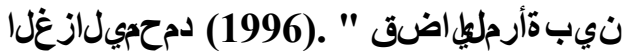

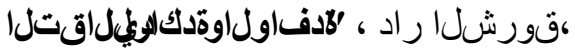

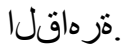

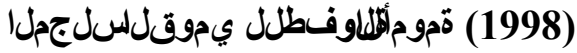

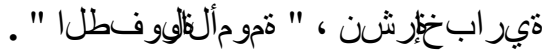

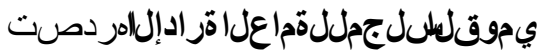

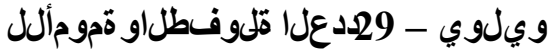
1998.

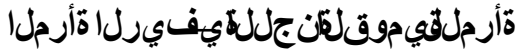

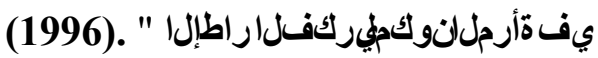

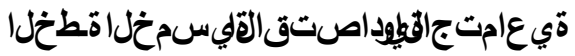
1996بوسيد ، 2002 - 1997 ـ (1999).

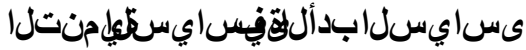

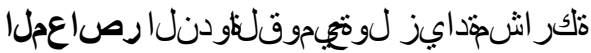

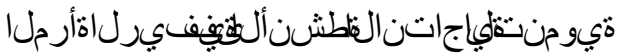

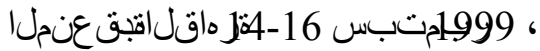

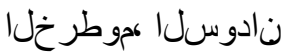




\section{ىب حي ناحير}

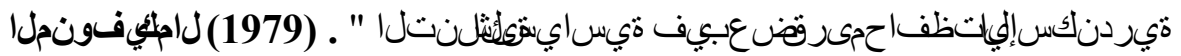

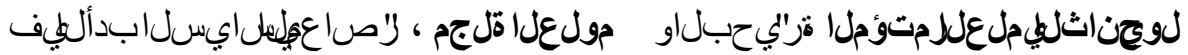

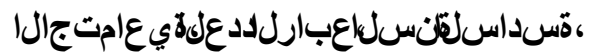

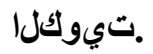

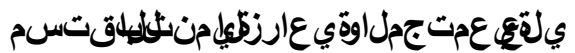

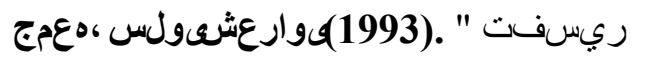

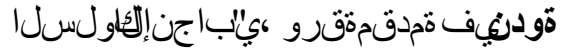

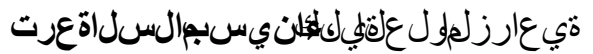

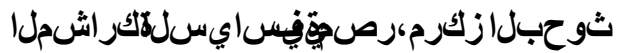

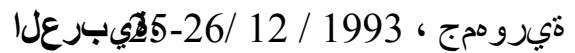

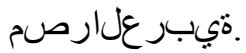
وحن " . (2000\$يعامشقلباببنانالسر

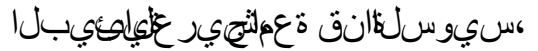
تبيبر علارصمةتيروهمج

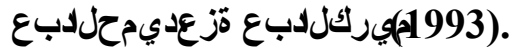

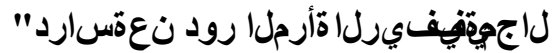

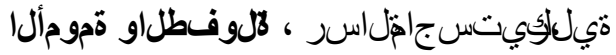

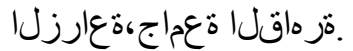

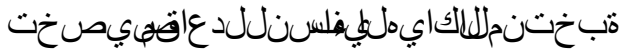

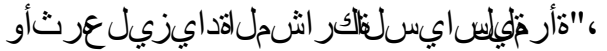
.

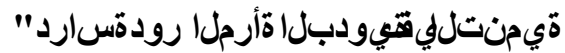

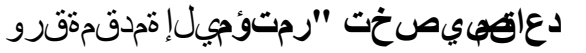

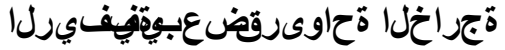

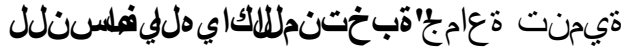

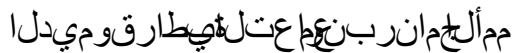

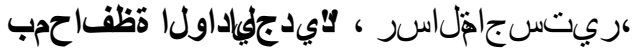

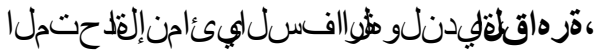

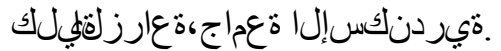
23 - 24 2000

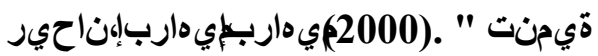

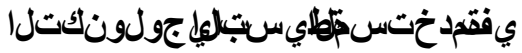

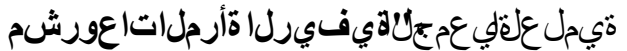

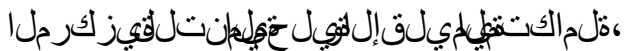

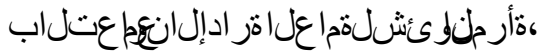

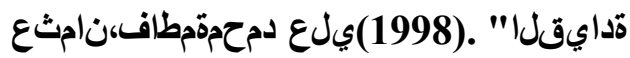

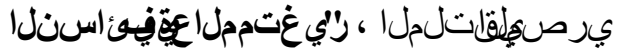

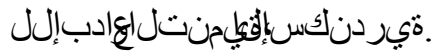

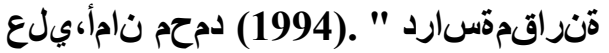

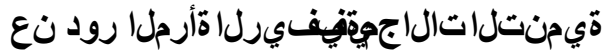

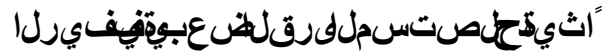

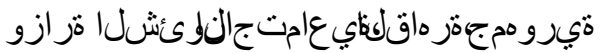

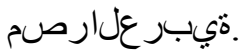

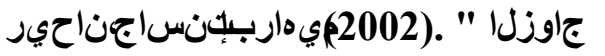

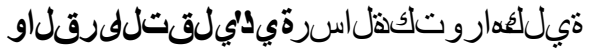

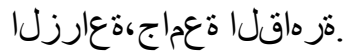

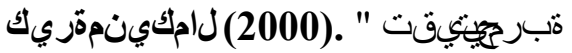

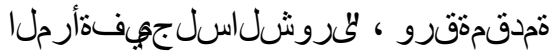

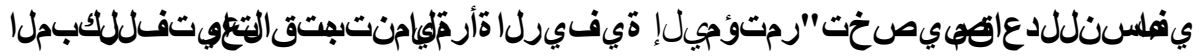

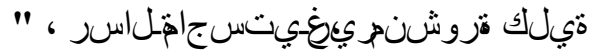
ثيمنت ةعامج ةتبّختن

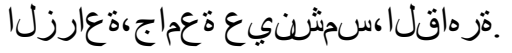

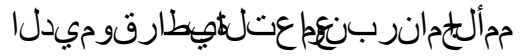

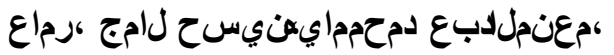

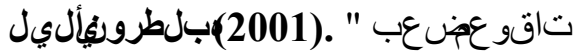

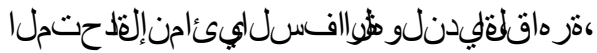
23 - 24 2000 .

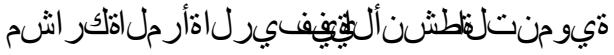




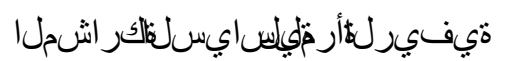

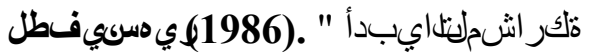

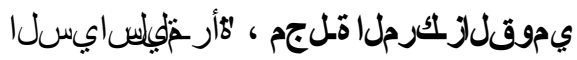

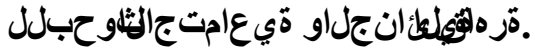

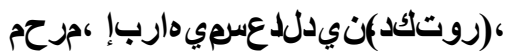

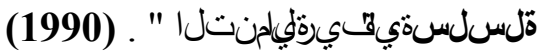

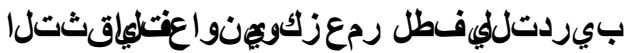

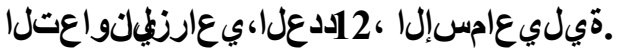
دومحم دمحم \&لغيدلدعسريهاربإ ،مرحم ،

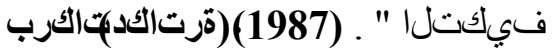

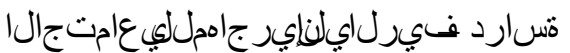

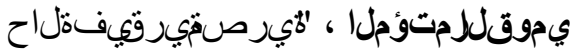

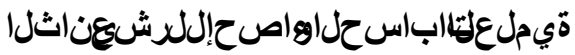

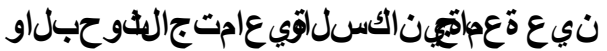

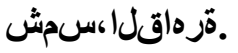

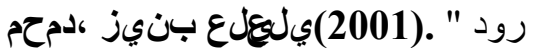

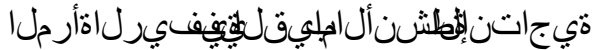

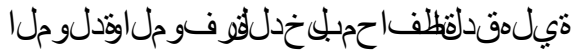

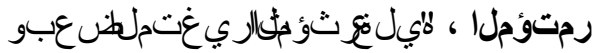

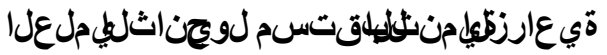

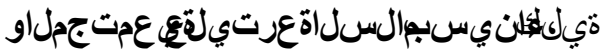

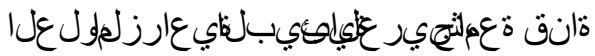

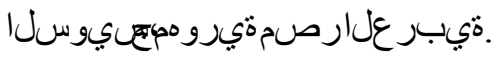

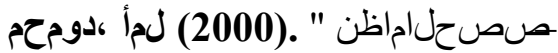
يلإةمدقمةقرو ةبيّايسرظن ة.

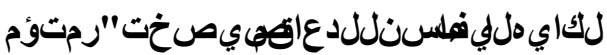

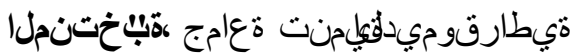
ي ئأن إلتلحت

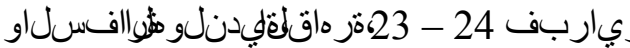
2000 .

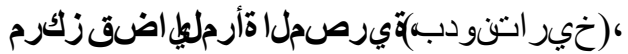

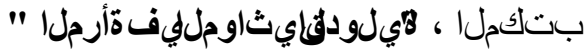

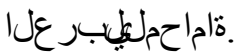

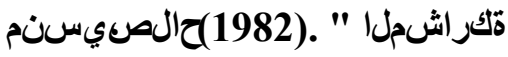

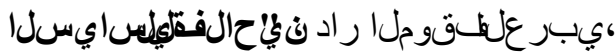

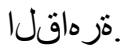

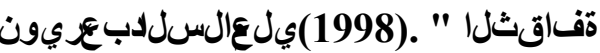

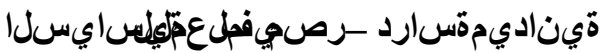

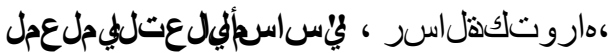

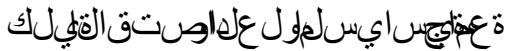

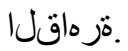

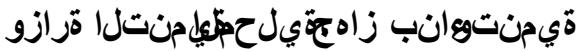

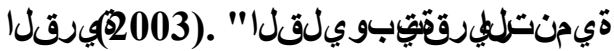

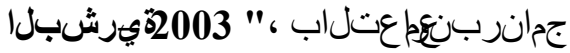

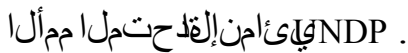

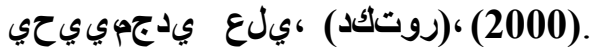

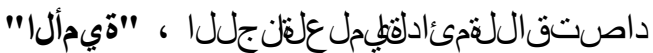

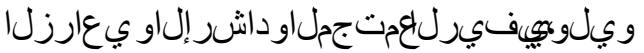
2000.

قيزيلجنالاعجارمثاليناث

El-Tigani, E.; El-Tigani (2000). "Changes in Family - Building and Patterns in Egypt and Morocco: A comparative Analysis “, Vol. 26, No. 2, The Alan Guttmacher Institute. Jedlicka, Allen D. (1975). "Issues and comments on the need to include women in the introduction and use of small technologies in less-developed countries", Issues paper prepared for the American Association for the Advancement of Science seminar on 


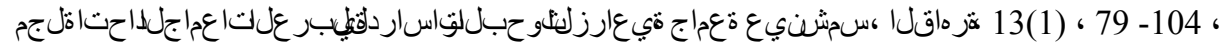
2005

women and development, June (14-18)

1975, Mexico City.

Gomaa, S. Shaarwi, (1998). "Political

Participation of Egyptian Women“,

The American University: Social

Research Center, Cairo.
Ranna, Hader, (1995). Gender and

Development, The American University, Cairo, Press, 1995.

Unicef Amman, (1995). "Ending Gender Disparities In The Arab World", A Profile on the Situation of Girls in the Region.

Arab Univ. J. Agric. Sci., Ain Shams Univ., Cairo, 13(1), 79-104, 2005

\title{
IMPACT OF DOMESTIQUE CULTURE VARIATIONS ON THE DEGREE OF POLITICAL PARTICIPATION FOR RURAL WOMEN IN EGYPT
}

\author{
Rihan. Ibrahim ${ }^{1}$, I. and Magdi A. Yehia ${ }^{1}$
}

\begin{abstract}
The recent study aims to identify the Impact of Domestique culture variations on the degree of political participation for rural women at two different sub-cultures in rural Egypt. In addition identify factors affecting the degree of rural women participation in political issues. In order to accomplish the study objectives, Qalubiya Governorate was selected to represent the culture of Lower-Egypt Governorates, and Minia Governorate was selected to represent the culture of Upper-Egypt Governorates. Each Governorate's administrative districts were divided into three categories (High, Medium, Low) based upon their human development indices, related to status of woman at those communities. Two districts were selected randomly from the medium category of the common human development index, Banha district from Qalubiya Governorate, and Maghagha district from Minia Governorate. From each of those districts two local village units were randomly selected. Within each of those previously mentioned villages, a random sample of 160 rural women was selected, and the total sample was 640 rural women. A questionnaire was designed and collected using the personal interview (after it was pre-tested) during August, September, and October 2003, then the data were tabulated and analyzed by using $\mathrm{X}^{2}$ coefficient. The study findings showed that about $43 \%$ of the total sample have low level of political participation, medium category represents about $28 \%$, and high category of the political participation

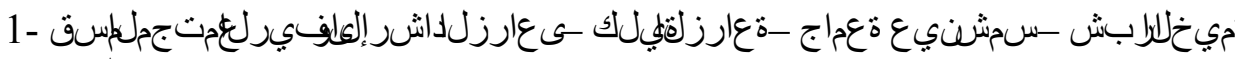

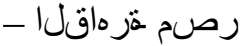

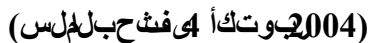

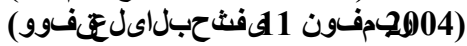




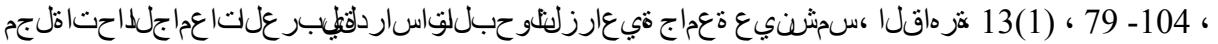
2005

represents about $29 \%$ of the total sample. Although, the elements of local culture different in Lower and Upper-Egypt, the study findings indicated that no differences were found between the two communities according to the average of the political participation degree of rural woman. The results revealed by using $x^{2}$ test that thirteen variables affecting the degree of rural women political participation indicator concerning the study explained about $37 \%$ of the total variance of the political participation of the rural woman. Those variables were: respondent education status, respondent age, monthly family income, husband education status, social status of the woman, respondent degree of informal social participation, husband age, the degree of developmental awareness, respondent occupation, the basic occupation of the husband, number of the family members, exposure to media sources, finally respondent Psychological health.

Key words: Domestique culture variations, Rural women, Political participation

1- Rural Sociology \& Agric. Extension Dept., Faculty of Agric., Ain Shams Univ., Shoubra El-Khema Cairo, Egypt

(Received October 4, 2004)

(Accepted November 11, 2004)

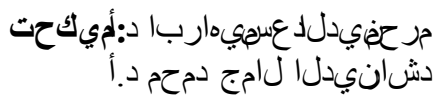

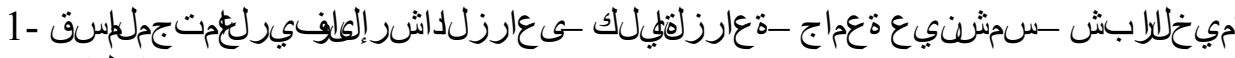

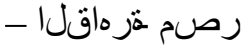

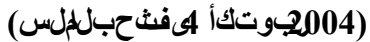

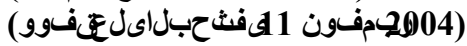

